\title{
Projections of North American Snow from NA- CORDEX and their Uncertainties, with a Focus on Model Resolution
}

Rachel McCrary ( $\sim$ rmccrary@ucar.edu )

National Center for Atmospheric Research https://orcid.org/0000-0003-0741-6773

Linda Mearns

National Center for Atmospheric Research

Mimi Hughes

NOAA Physical Sciences Division

Sébastien Biner

Ouranos

Melissa Bukovsky

National Center for Atmospheric Research

\section{Research Article}

Keywords: climate change, snow, regional climate modeling, North America, CORDEX

Posted Date: August 11th, 2021

DOI: https://doi.org/10.21203/rs.3.rs-790781/v1

License: (9) This work is licensed under a Creative Commons Attribution 4.0 International License. Read Full License

Version of Record: A version of this preprint was published at Climatic Change on February 1st, 2022. See the published version at https://doi.org/10.1007/s10584-021-03294-8. 
2 Projections of North American Snow from NA-CORDEX

3 and their Uncertainties, with a Focus on Model

4 Resolution.

5

6

Initial submission to Climatic Change on 31 August 2021

7

Resubmitted to Climatic Change on 5 August 2021

8

9 Keywords: climate change, snow, regional climate modeling, North America,

CORDEX

11

12

13

14

15

16

17 


\section{Abstract}

Snow is important for many physical, social, and economic sectors in North America. In

20 a warming climate, the characteristics of snow will likely change in fundamental ways, therefore

21 compelling societal need for future projections of snow. However many stakeholders require

22 climate change information at finer resolutions that global climate models (GCMs) can

23 provide. The North American Coordinated Regional Downscaling Experiment (NA-CORDEX)

24 provides an ensemble of regional climate model $(\mathrm{RCMs})$ simulations at two resolutions $\left(\sim 0.5^{\circ}\right.$

25 and $\sim 0.25^{\circ}$ ) designed to help serve the climate impacts and adaptation communities. This is the

26 first study to examine the differences in end-of-21st-century projections of snow from the NA-

27 CORDEX RCMs and their driving GCMs.

28 We find the broad patterns of change are similar across RCMs and GCMs: snow cover

29 retreats, snow mass decreases everywhere except at high latitudes, and the duration of the snow

30 covered season decreases. Regionally, the spatial details, magnitude, percent, and uncertainty of

31 future changes varies between the GCM and RCM ensemble, but are similar between the two

32 resolutions of the RCM ensembles. Increases in winter snow amounts at high latitudes is a

33 robust response across all ensembles. Percent snow losses are found to be more substantial in the

34 GCMs than the RCMs over most of North America, especially in regions with high-elevation

35 topography. Specifically, percent snow losses decrease with increasing elevation as the model

36 resolution becomes finer. 


\section{1. Introduction}

41 Terrestrial snow plays a key role in the climate, ecology, hydrology, and economies of

42 North America (NA). Snow's high albedo alters the surface energy budget consequently

43 influencing both long-term climate and short-term weather (e.g. Vavrus, 2007). It also provides

44 an important habitat for wildlife that are adapted to living in snow conditions (Campbell et al,

45 2005; Barsugli et al, 2020). Seasonal snow accumulation is a natural reservoir for water storage

46 and the timing and amount of snowmelt is critical for water supply (Barnett et al, 2005),

47 agriculture (Qin et al, 2020) and hydropower production (Markoff and Cullen, 2008. The timing

48 and amount of snowmelt is linked to droughts (Harpold, 2016) and wildfires (Westerling et al,

49 2006). Snow is crucial for winter transportation (Palko and Lemmen, 2018) and tourism (e.g.

50 skiing, snowmobiling, snowshoeing; Chin et al, 2018; Wobus et al, 2017) which drive regional

51 economies (Burakowski and Magnusson, 2012). In addition to the many benefits of snow, it also

52 contributes to a wide range of hazards including damages to roads and buildings (Palko and

53 Lemmen, 2018; Jeong and Sushama, 2018), avalanches (Campbell et al, 2007) and spring

54 flooding (Berghuijs et al, 2016).

Future changes in snow conditions associated climate change will have important

56 implications for all of these sectors. This drives a strong societal need for regional projections of

57 snow and their uncertainties. Researchers and stakeholders alike need such information to

58 determine the regional and local impacts of future changes in snow as well as to inform decision

59 makers regarding how to adapt to future changes.

Changes in snow result from the combined interactions between increasing temperatures

61 and changing precipitation patterns. Future projections of snow for NA have been investigated

62 using modeling techniques across multiple time and space scales including global climate models 
63 (GCMs; Raisanen, 2008; Brown and Mote, 2009; Mudryk et al, 2020, Krasting et al, 2013),

64 regional climate models (RCMs; McCrary and Mearns, 2019; Rhoades et al, 2018a; Rasmussen

65 et al, 2011), variable resolution climate models (Rhoades et al, 2018b), and statistical

66 downscaling applied to hydrologic models (Christensen and Lettenmaier, 2007; Notaro et al.

67 2014). These studies show that increasing temperatures will dominate the climate change signal

68 over most of NA resulting in widespread decreases in snowfall, snow cover extent and duration,

69 and snow water equivalent (SWE). However, mid-winter snowfall and SWE may increase over

70 the cold high latitudes and high elevations (Raisanen, 2008; McCrary and Mearns, 2019;

71 Rasmussen et al., 2011).

72 The North American Coordinated Regional Downscaling Experiment (NA-CORDEX;

73 Mearns et al, 2017) consists of an ensemble of regional climate projections for NA where

74 multiple RCMs were driven with boundary conditions from multiple GCMs to produce

75 downscaled climate projections at two resolutions $\left(\sim 0.5^{\circ}\right.$ and $\left.\sim 0.25^{\circ}\right)$. NA-CORDEX fills a need

76 for scientists and stakeholders who desire spatially uniform and consistent climate change data at

77 higher resolutions than GCMs can provide, and with enough models to explore uncertainty.

78 RCM ensembles like NA-CORDEX are heavily used across multiple disciplines in order to study

79 climate change and its impacts (Mearns et al, 2015; McGinnis and Mearns, 2021). While there

80 exists an abundance of papers examining temperature and precipitation projections in RCM

81 ensembles, far fewer studies have looked at snow, even over Europe where CORDEX

82 simulations have been available for longer.

83 Our goal here is to evaluate snow and examine future changes and their uncertainties in

84 the NA-CORDEX RCMs and their driving GCM simulations. Since NA-CORDEX provides

85 downscaled simulations at two resolutions, we focus on the differences between the RCM and 
86 GCM ensembles to identify what, if any, additional information is gained by increasing

87 resolution from GCM scales (ranging from $1.25^{\circ}$ to $2.8^{\circ}$ ) down to $0.5^{\circ}$ and $0.25^{\circ}$. To do this we

88 performing a side-by-side comparison of the GCMs and RCMs used in NA-CORDEX, parsing

89 NA-CORDEX by resolution. We focus on how the spatial distribution, magnitude, and percent

90 change of future projections and their uncertainties differ across the ensembles. Our analysis

91 starts broadly over all of NA, but then narrows down to three unique regions (Figure 1a) to

92 further explore regional differences in model fidelity and future change.

93 2. Models, Datasets, and Methods

\section{$94 \quad 2.1$ Models}

In NA-CORDEX, multiple RCMs were driven with boundary conditions from multiple

GCMs that were part of phase 5 of the Coupled Model Intercomparison Project (CMIP5; Taylor

97 et al. 2012). Many of the RCMs simulations in NA-CORDEX were performed at two

98 resolutions $\left(0.44^{\circ}\right.$ or $50 \mathrm{~km}$ and $0.22^{\circ}$ or $25 \mathrm{~km}$, depending on the model configuration). All RCM

99 simulations cover at least 1951-2098, and future projections (2006-2098) follow the

100 Representative Concentration Pathway 8.5 (RCP 8.5). In this work the historical time period

101 spans 1976-2005 and the end-of-21st-century future time period spans 2070-2098.

102

Only a subset of the NA-CORDEX simulations have SWE output available (Table 1).

103 Although SWE is available from the RegCM4 NA-CORDEX simulations (na-cordex.org),

104 unbounded snow accumulation was found to occur in many mountainous regions this RCM was

105 excluded from the analysis (Supplemental Information (SI) Section S1). We split the NA-

106 CORDEX models into two climate ensembles based on resolution. As discussed more in Section

1072.3 .2 , we regrid the $0.44^{\circ} / 50 \mathrm{~km}$ simulations to a common $0.5^{\circ}$ grid, and the $0.22^{\circ} / 25 \mathrm{~km}$ 
108 simulations to a common $0.25^{\circ}$ grid. Throughout the paper we refer to these ensembles as either

109 NA-CORDEX-0.5 ${ }^{\circ}$ (8 members) or NA-CORDEX-0.25 $(11$ members $)$.

110 Of the 7 driving GCMs used in NA-CORDEX, daily SWE was available from 6 (Table

111 1). Throughout the paper we refer to this set of 6 GCMs as the CMIP5-Driver ensemble. We

112 also look at broad changes in SWE from all of the models in CMIP5 with daily SWE output

113 which we refer to as the CMIP5-ALL ensemble (SI Table S1, 18 members). In our analysis, the

114 the CMIP5-All ensemble is included on all timeseries plots, but not on the spatial maps.

\section{$115 \quad 2.2$ Snow Datasets}

116 A major challenge for evaluating SWE in climate models is a lack of long-term, high-

117 resolution (spatial and temporal), well-vetted gridded observations (e.g. McCrary et al,

118 2017). The insufficiency of snow observations has led many to create gridded SWE datasets that

119 are observationally-constrained and informed by models, which we call Modeled-Observations,

120 or MObservations (MObs). These include atmospheric and land-surface reanalysis products and

121 statistical and physical models that are constrained by in-situ snow observations.

122 Following McCrary et al, (2017) we use a multi-dataset approach to capture the

123 uncertainty in observed snow by creating an ensemble of MObs datasets (Table 2). All of the

124 MObs datasets included are gridded products with $0.25^{\circ}$ or finer resolution, at least 5 years of

125 data between 1981-2010, and cover CONUS or North America. These datasets have considerable

126 uncertainties related to sparse observational networks and surface meteorological forcing,

127 satellite retrieval algorithms, and the use of models that must parameterize snow processes.

128 While this ensemble will not capture the full uncertainty in snow observations, it serves as a

129 reference dataset in which to assess the climate models used in this study. 
Optical satellite products can be used to identify the presence of snow. To evaluate snow

131 cover metrics we include the Interactive Multisensor Snow and Ice Mapping System (IMS)

132 24km daily snow cover dataset (U.S. National Ice Center, 2008) in combination with snow cover

133 estimated from the SWE MObs.

\section{$134 \quad 2.3$ Methods}

135 2.3.1 Calculation of Snow Cover

Similar to McCrary and Mearns (2019), we calculate snow cover from SWE by applying

137 a 5mm threshold to daily SWE fields from the MObs and the simulations to produce a binary

138 yes-no snow cover field. Snow cover extent (SCE) is calculated by first averaging this binary

139 field over each month to produce monthly snow cover fraction (SCF) at each gridbox and then

140 summing over NA. The daily binary snow cover field is also used to calculate snow cover

141 duration (SCD), defined as the number of days with snow on the ground. SCE, SCF and SCD

142 are also calculated from the satellite IMS dataset which provides estimates of yes-no snow cover.

143 2.3.2 Removal of Snow-On-Ice Grid Points

144 Snow-on-ice (sea ice or land ice) is a complex process that is not well simulated by many

145 climate models. We remove any points which may be ice covered or strongly influenced by

146 land/sea ice. As most modeling centers do not provide information about ice-free land points,

147 we have applied two methods to remove these points. First, we exclude Greenland and the

148 Canadian Arctic Archipelago from our analysis. While changes in snow over these regions will

149 have important implications for the overall climate, shipping/transportation, and arctic

150 ecosystems, we feel such analysis is beyond the scope of this study. Second, some models

151 accumulate permanent snow over grid points within the Coast Mountains in British Columbia 
152 because snow does not entirely melt during summer. This results in high snow mass values and

153 these points effectively turn into glaciers. To account this we have removed all grid points

154 where SWE exceeds $1000 \mathrm{~kg} \mathrm{~m}^{-2}$ during August.

$155 \quad$ 2.3.2 Ensemble Analysis

156 As regridding snow onto different grids can greatly impact mass budgets, regionally

157 averaged time series plots are calculated on the native grids of the climate models. However,

158 since each model uses a different grid, for ensemble mean spatial calculations we regridded the

159 MObs and models to common grids using conservatie remapping. The CMIP5 models have

160 been regridded to a $1.5^{\circ}$ grid, and the NA-CORDEX ensembles have been regridded to $0.5^{\circ}$ and $1610.25^{\circ}$.

\section{3. Results}

\section{3.1 Evaluation of Climate Models}

164 In the following section we compare the historical simulations from the CMIP5 and NA165 CORDEX ensembles with the MObs ensemble.

166 3.1.1 Snow Cover Extent

167 The annual cycle of SCE from the MObs and climate models is shown in Fig 2. Only, 168 IMS, ERA5-land and GLDAS-noah have data that covers all of NA. The timing of the annual 169 cycle of SCE in the MObs follow each other closely. SCE is near zero in July-August, starts to 170 increase in September, reaches a maximum in January and declines throughout the spring and 171 early summer. In general GLDAS-noah has much lower values that IMS or ERA5-land.

172 Between December-April IMS has higher values than ERA5-land, otherwise the two datasets are 
173 closely matched the rest of the year. Spatially, the largest differences in January snow cover

174 fraction (SCF) occur in the Central Plains and Great Basin (SI Fig. S4.)

175 Ensemble mean SCE for the CMIP5-Driver and CMIP5-All ensembles are similar to each

176 other and fall within the range of the MObs (Fig. 2; individual models results SI Fig. S8). The

177 spread in historic SCE in the CMIP5-Driver ensemble is similar to the observed spread, while the

178 spread in the CMIP5-All ensemble is slightly larger than observed. In both NA-CORDEX

179 ensembles, the ensemble mean annual cycle of SCE is on the higher end of the MObs, following

180 the IMS dataset almost exactly, with half the individual RCMs slightly overestimating SCE

181 compared to IMS (SI Fig. S8). The spread in the NA-CORDEX-0.5 ensemble is larger than the

182 NA-CORDEX- $0.25^{\circ}$ ensemble. The spatial distribution of January snow cover fraction (SCF)

183 highlights where differences in simulated SCE arise (SI Fig. S5-S7).

184 3.1.2 Climatological SWE

Maps of ensemble mean annual maximum monthly SWE (AM-SWE) from the MObs and

186 climate simulations are shown in Fig. 3. For the MObs, ensemble mean AM-SWE is calculated

187 across all available datasets at each gridbox (Fig 3a-c). Although the spatial patterns of AM-

188 SWE are similar across the three resolutions, distinct topographic features such as the Sierra

189 Nevada's in California, the Cascade Range in the Pacific Northwest, and the Rocky Mountains

190 deteriorate with decreasing spatial resolution. Results from the individual MObs and MObs

191 ensemble statistics highlight the uncertainty across the MObs ensemble (SI Figs. S9-S12). In

192 this study we use them as a reference to qualitatively evaluate the models.

193 The spatial patterns of AM-SWE in the CMIP5-Driver and NA-CORDEX ensembles are

194 broadly similar to the MObs ensemble (Fig 3 d-f; individual model results SI Figs. S13-

195 15). Compared to the MObs ensemble mean, the CMIP5-Driver GCMs underestimate SWE in 
196 the mountains and overestimate SWE in the lower elevation regions of western NA (Fig. 3. d,g,j;

197 SI Fig. S16). As the mountains in these coarse GCMs are relatively smooth and low (Fig. 1b)

198 there is limited orographic enhancement of precipitation in the mountains resulting in too much

199 moisture penetrating inland, likely contributing to positive biases east of the mountain ranges in

200 the west (e.g., Rasmussen et al, 2011). In the CMIP5-Driver ensemble negative biases also occur

201 over the northeast NA including Ontario, Quebec, and the Northeast US. Outside of a few

202 regions in the western and eastern portions of the domain, AM-SWE in the CMIP5-Driver

203 ensemble generally falls within the uncertainty range of the MObs ensemble (SI Fig. S19) .

204 AM-SWE in the two NA-CORDEX ensembles differs from the MObs ensemble in

205 similar ways (Fig 3, h,i,k,1; individual model results SI Figs. S14-S15, S17-S18). The only real

206 difference is that the spatial details of SWE patterns are finer with increasing resolution. In both

207 ensembles, positive biases dominate over the domain, with only small areas experiencing

208 negative biases. Over the western half of the domain, AM-SWE is greatly overestimated on the

209 western side of the mountains and underestimated just east of the highest peaks of the mountains

210 (SI Fig. S20). Relative to the MObs ensemble mean, the magnitude of positive SWE biases are

211 larger in the mountains than the lower elevation regions, however, percent SWE biases are much

212 larger at lower altitudes. The percent bias figures (Fig. 3 j-1) highlight regions where the climate

213 models simulate snow but the MObs do not. When compared to the range of the MObs

214 ensemble, AM-SWE values in both RCM ensembles are greater than the MObs on the western

215 side of Mountain ranges, in the Central US, and Northern Canada/Alaska (SI Fig. 19).

216 The similarities in the AM-SWE bias patterns in the RCMs suggests that biases in large-

217 scale forcing and RCM configuration/parameterizations play a similar role in the simulation of

218 SWE at both resolutions. As the mountains in the NA-CORDEX simulations are higher than the 
219 GCMs, orographic precipitation is larger in the RCMs due to enhanced lifting (See Mahoney et 220 al, 2021) resulting in higher SWE values. However, winter precipitation in NA-CORDEX far

221 exceeds observations in the RCMs (Mahoney et al, 2021). This is possibly because even at $0.25^{\circ}$

222 convection is insufficiently resolved and convective parameterizations play a large role in

223 precipitation biases (Hughes et al.). The bias in precipitation likely translates to a positive bias in

224 SWE, however SWE biases will also be linked to temperatures the evolution of snowpack in the 225 RCMs (McCrary et al., 2017).

\section{3.1.3 Snow Cover Duration}

Another key characteristic of NA snow that may change in the future is the length of the

228 snow covered season or SCD. In the MObs, SCD increases with latitude and elevation (Fig. 4a-

229 f; individual MObs in SI Figs. S21-S23). The broad spatial patterns of SCD are similar across

230 the different resolutions, but the details are lost as resolution coarsens. Much like winter SWE

231 values, $\mathrm{SCD}$ is reduced in the mountains when aggregated to coarse scales (Fig. 4a).

232 The CMIP5-Driver GCMs underestimate SCD in the mountains and most of the eastern

233 half of the domain, although SCD is positively biased at low-elevation regions in the western

234 half of the domain (Fig. 4g; individual models results SI Fig S24). Both RCMs ensembles

235 overestimate SCD over the entire domain, with larger biases at lower-elevation in the Great

236 Basin and east of the middle and southern Rockies (Fig. 4h,i; individual model results SI Figs.

237 S25-S26 ).

$238 \quad 3.2$ Future Change over North America

239

3.2.1 Snow Cover Extent 
SCE is projected to decrease in all months of the year in all of the models examined (Fig.

241 2, c-d; individual model results SI Fig. S8). The largest percent losses are projected to occur in

242 October, May and June when snow cover is marginal in the historic climate period. Average

243 SCE losses are larger in both CMIP5 ensembles than both NA-CORDEX ensembles. Although

244 ensemble mean changes in SCE are similar for the CMIP5-Driver and CMIP5-All model

245 ensembles, the uncertainty (measured here as the multi-model spread) is considerably larger in

246 the CMIP5-All ensemble. This may indicate that our subset of CMIP5 models does not capture

247 the full potential of the combination of temperature and precipitation changes that drive changes

248 in snow. The NA-CORDEX $0.5^{\circ}$ and $0.25^{\circ}$ ensembles have nearly identical projections for SCE

249 loss. The uncertainty in future SCE changes is slightly larger in the NA-CORDEX ensembles

250 than the CMIP5-Driver ensemble during October-February but slightly smaller in March-July.

\section{3.2.2 Annual Maximum SWE}

All three model ensembles project large-scale losses in AM-SWE over most of the

253 domain, with the exception of the high-latitude regions of Canada and Alaska (Fig. 5; individual

254 model results SI Figs. S27-S32). These results are consistent with previous studies (McCrary

255 and Mearns, 2019; Raisanen, 2008). Absolute losses are larger in the mountain over the western

256 and eastern portions of the domain, while percent losses are higher at low latitudes and lower

257 elevations. Total snow losses are projected in all of the ensembles along the southern edge of the

258 snow boundary (Fig 5. d-f). The individual models in all of the ensembles also show total losses

259 along the southern snow boundary (SI Figs. S28, S30, S32).

260 While the three ensembles tell broadly the same story, details emerge in the RCMs, that

261 are not found in the GCMs. Focusing on percent change, as it reduces the influence of simulated

262 difference in baseline historical AM-SWE amounts, it is apparent that percent losses are 
263 generally larger in the CMIP5-Driver ensemble both of the NA-CORDEX RCM ensembles,

264 especially in regions of complex topography. By the end of the $21^{\text {st }}$ century, the CMIP5-Driver

265 ensemble projects that $50.5 \%$ of NA will experience AM-SWE losses of greater than $50 \%$ and

266 that $15.9 \%$ of NA will experience losses of greater than $90 \%$. Comparatively the NA-

267 CORDEX $-0.5^{\circ}$ (NA-CORDEX- $0.25^{\circ}$ ) ensembles project greater than $50 \%$ losses over only

$26838.9 \%$ (36.4)\% of NA and $90 \%$ losses over only $9.16 \%$ (8.8\%). The reduced losses in the RCMs

269 is partially due to the fact that they have more higher-elevation mountain points (Fig. 1 and

270 Section 3.1.1) where temperatures can remain below freezing during winter. But also, percent

271 change is affected by the historical snow amount where for the same magnitude loss, smaller

272 percentage loss will be found if there is more SWE in the historical baseline climate.

\section{3.2.3 Snow Cover Duration}

274 Along with losses in SCE and SWE, the duration of the snow covered season is also 275 projected to decrease (Fig. 4, j-1; individual model results SI Figs S33-S35). The largest

276 decreases in SCD are found over the mountains in the western half of the domain, over

277 Southwestern Alaska, and the eastern half of Newfoundland/Labrador and New England. While

278 the broad spatial patterns of changes in SCD are similar across the ensembles, again the spatial

279 details are lost in the GCMs. For example, in the western mountains the RCMs demonstrate that

280 SCD will decrease more at higher elevations than lower elevations. While AM-SWE is

281 projected to increase at high-latitudes (Fig 5) and at high-elevations in a few of the models (SI

282 Figs. S28, S30, S32), SCD is found to decrease everywhere, indicating while AM-SWE may

283 increase in some locations, the snow covered season will still contract.

$284 \quad 3.3$ Regional Changes 
In the previous section we explored the continental-scale patterns of changes in snow conditions over NA. While important from a large-scale climate perspective, most researchers

287 and stakeholders often want to know what will happen over smaller-scale regions. Here we

288 zoom in on three unique climate regions, to explore more deeply how resolution influences

289 future projections of SWE. These regions (Fig. 1a) are, the U.S. Intermountain West (IMW),

290 North-Central Canada (NC-Canada), and Northeast U.S. and Southeast Canada (referred here as

291 the Northeast). The considerable changes in snow projected along the west-coast of the domain

292 in the NA-CORDEX models have been explored in Rhoades et al. (2018a) and Mahoney et al.

293 (2021).

\section{3.3.1 U.S. Intermountain West (IMW)}

The IMW region is large and contains portions of the middle and southern Rocky

296 Mountains and the Great Basin (Fig. 1a). We chose this region because of its complex

297 topography including high elevation mountains where seasonal snowpacks and spring snowmelt

298 are critical for water supply, ecosystem health, forest fire risk, and recreation.

299 First we examine the annual cycle of monthly averaged total snow mass (SM) for the

300 region (Fig. 6 a,d; individual models results SI Fig. S36). The observational uncertainty is very

301 high as the MObs disagree on the magnitude of SM during most months of the year (excluding

302 August and September) and the timing of peak SM (showing either a February or March

303 maximum). There is a clear separation between the 4 highest MObs and the 4 lowest MObs over

304 the region. Lundquist et al. (2020) demonstrated that most snow reanalysis datasets

305 underestimate SWE in the mountains, so our judgement here is that datasets with higher SM

306 values are more realistic. GLDAS-noah snow values are likely unrealistic in this area as the 
307 GLDAS forcing dataset has a dry bias (Henn et al, 2018) and the Noah land surface model

308 underestimates SWE in the mountains (e.g. Livneh et al, 2010).

309 The spread in historical SM in both CMIP5 ensembles is large and comparable to the

310 MObs uncertainty. Ensemble mean SM in the GCMs falls within the middle of the MObs range.

311 The NA-CORDEX ensembles have considerably more snow than their driving GCMs and about

312 half the spread during peak months. Between December-April, ensemble mean SM in the RCMs

313 falls within the 4 highest MObs, but spring snowmelt occurs more rapidly in the RCMs than

314 those same datasets.

315 To examine future changes in regional SM, we again primarily focus on percent changes

316 (Figure $6 \mathrm{~h}, \mathrm{k}$ ), however, the annual cycle of future snow and the magnitude of snow changes are

317 shown in SI Fig. S37. Average IMW SM is projected to decrease for all months of the year in all

318 of the models, except for one CMIP5-ALL ensemble member (Fig. 6, h,k). Regional percent SM

319 losses are smaller in the NA-CORDEX ensembles than the CMIP5 ensembles and. For example,

320 in March (around the timing of peak snow amounts) SM is projected to decrease by $84.1 \%$ in

321 CMIP5-ALL, 76.8 in CMIP5-Driver, 58.2\% in NA-CORDEX-0.5 ${ }^{\circ}$, and 52.4\% in NA-

322 CORDEX $-0.25^{\circ}$. The uncertainty in future losses is also much larger in the GCM ensembles

323 than the RCM ensembles. For example, in March the spread in future change is 2.05 times larger

324 in the CMIP5-ALL ensemble than the NA-CORDEX- $0.25^{\circ}$ ensemble. In most of the models the 325 largest absolute SM losses occur when historical maximum SM occurs, and the timing of peak

326 SM occurs one month earlier in the future (SI Fig. S36-S37).

327 Fig. 7 examines the spatial distribution of historical and future changes in AM-SWE

328 over the IMW. Terrain plays a large role in determining precipitation, snowfall and SWE

329 patterns in the IMW. In the coarse CMIP5-Driver GCMs, topography is fairly smooth and the 
330 Rocky Mountains are captured as one mountain feature (Fig 7a) although this varies slightly with 331 GCM, see SI Fig. S38). With increasing resolution, individual mountain ranges begin to appear 332 and become more distinct (Fig 7b-c). Comparisons of the distribution of elevation over the IMW 333 (Fig. 8a) highlights that all of the ensembles, but in particular the CMIP5-Driver ensemble, have 334 too many grid points at mid-elevations between $1500-2500 \mathrm{~m}$ and too few points at lower 335 elevation valleys and higher elevation mountains.

336 In both the historical and future simulations, AM-SWE generally increases with elevation 337 and latitude (Fig 7d-i; individual models SI Figs. S39-S41). As with topography, distinct spatial 338 patterns of SWE become more refined with increasing resolution. Also, the orographic 339 enhancement of precipitation and snowfall becomes evident as resolution increases and taller 340 mountains are represented. Comparison to the MObs AM-SWE (SI Fig. 20) reveals unrealistic 341 patterns in the CMIP5-Driver ensemble related to the GCMs' unrealistic underlying terrain, as 342 the Middle and Southern Rockies should have distinct peaks in SWE.

343 By the end of the century, ensemble mean AM-SWE is projected to decrease at all 344 gridpoints over the IMW region in all of the ensembles, (Fig. 7 g-i) although some individual 345 models do have regions with small increases (SI Figs. S42-S47). In terms of magnitude, the 346 largest losses generally correspond with the largest historical SWE values (in the high elevations 347 and northern part of the domain) (Fig. 7j-1; individual model results SI Figs S42-S44). However, 348 the largest percent losses can be found at lower elevation, lower latitude regions, with smaller 349 percent losses projected at high elevations (Fig. 7m-o; individual model results SI Figs S45-S47). 350 The RCM ensembles both have lower percent losses than the GCMs in many areas, which appear 351 for the most part to correspond with higher topography. Although temperatures are projected to 
352 increase everywhere over the IMW, we might expect higher-elevation SWE to be partially

353 preserved as temperatures can still remain below freezing during the heart of winter.

354 To further explore the relationship between elevation and snow over the IMW we bin

355 annual maximum snow mass (AM-SM) over the IMW by elevation (Fig. 8). To calculate AM-

356 SM we take the climatological AM-SWE (e.g. Fig 7) from each model and the four highest

357 MObs in Fig. 6a and calculate the mass of snow stored in each elevation bin for each dataset.

358 None of the datasets have grid points below 500m, the CMIP5-Driver models have no

359 grid-points above $3000 \mathrm{~m}$, and only the MObs and the NA-CORDEX- $0.25^{\circ}$ ensemble have grid-

360 points above $3500 \mathrm{~m}$ (Fig. 8a). Most of the observed AM-SM occurs between 2000-3000m (Fig.

361 8b), with lower values at higher and lower elevations. In the climate models, most of the AM-

362 SM occurs at lower elevations, between $1500-2500 \mathrm{~m}$. On average the RCMs overestimate AM-

363 SM at mid elevations (1500-2500m) and underestimate AM-SM above $2500 \mathrm{~m}$, with larger biases

364 in the NA-CORDEX- $0.5^{\circ}$ ensemble. The GCMs skew toward negative AM-SM biases, except

365 between $1500-2000 \mathrm{~m}$, where ensemble mean values are slightly higher than observed. There is

366 also large uncertainty in historical AM-SM in the CMIP5-Driver ensemble between 1500-

$3672500 \mathrm{~m}$, likely linked with the large spread horizontal resolution and topography (SI Fig S38 and

368 Fig 8a).

369 In terms of magnitude, the largest losses in AM-SM for all the models occurs between

370 1500-2500m, corresponding with the elevations bins with the largest historical AM-SM. Percent

371 losses in the CMIP5-Driver GCMs are also highest between 1500-2500m, but in the RCMs,

372 percent losses are highest at lower elevations (1000-2000m). In all the models, percent losses

373 steadily decrease above $2000 \mathrm{~m}$, where temperatures will remain below freezing more frequently

374 than the lower elevation bins. Since vast majority of gridpoints in the GCMs occur between 
375 1500-2500m where the largest AM-SM losses (magnitude and percent) occur and the GCMs

376 have no gridpoints at the higher elevation bins, this supports the idea that reduced relative snow

377 losses occur in the RCMs because they have higher mountain elevations, which help to buffer

378 snow losses. However, percent AM-SM losses are higher in the GCMs at all elevation bins,

379 which suggests differences are not solely due to elevation, but also related to baseline SM

380 amounts (Fig. 8b) and the magnitude of total SM loss that occurs in each elevation bin (Fig. 8c)

381 3.3.3 North-Central Canada (NC-Canada)

382 We next examine changes over North-Central Canada (NC-Canada, Fig. 9) as this is the

383 one area of NA where the climate model ensembles project potential increases in winter

384 snowpacks. In this region, increases in SWE could have important implications for winter

385 transportation, wildlife, and indigenous populations. Here we examine how robust these

386 projected changes are.

387 Only four members of MObs ensemble have SWE data for NC-Canada, and there are

388 large difference between them (Fig 6b,e; individual model results SI Fig. S48). Also, given the

389 very few in-situ observations (snow or surface meteorology) over the region (e.g. Mekis et al,

390 2018), observed snow amounts are highly uncertain. Over NC-Canada, much of the year is snow

391 covered, with only a short snow-free period in summer. Snow accumulates between October and

392 March/April and declines quickly between March/April and July, with the timing of peak SM

393 varying across the datasets. Over the region, ERA5-land has the highest SM values, GLDAS-

394 noah has the lowest values, and CMC and GlobSnow fall in between. Values are likely

395 underestimated in GlobSnow, as the mountains in the south-west part of the domain are masked

396 (see SI Fig. S11). SM in all four of the model ensembles lie on the upper-end of the MObs 
estimates (following ERA5-land). The simulated uncertainty is higher in the GCM simulations

398 than the RCM simulations and the RCMs tend to have more snow than the GCMs.

In the future, losses are projected in all of the models examined between May-

400 November. However, from December-April most of the RCMs and many of the GCMs project

401 up to $20 \%$ increases in SM for the region. Snow increases in this region are likely associated

402 with increases in the amount of moisture in the atmosphere associated with warming

403 temperatures which result in increases in precipitation and snowfall, as winter temperatures

404 remain well below freezing (Raisanen, 2008). In the future the timing of peak SM occurs one

405 month earlier in most of the models, and the largest magnitude changes in SM occur in May for

406 all ensembles (SI Figs. S48-S49).

407 Spatially, most of the increases in AM-SWE occur over the northern and eastern portions 408 of the domain (Fig 9) although this is model dependent (SI Figs. S50-S58). At individual points, 409 ensemble mean AM-SWE increases by $1-50 \mathrm{~mm}$ or $1-20 \%$. The areal extent over which AM-

410 SWE is projected to increase is largest in the NA-CORDEX- $0.5^{\circ}$ ensemble, and smallest in the

411 CMIP5-DRIVER ensemble. All of the models in all of the ensembles project increase in SWE

412 along the northern edge of continental Nanavut (Fig. 9, g-i); however, model agreement

413 regarding where increases in SWE may occur is lower for the west and south of the domain.

\section{3.3.3 Northeast U.S. and Southeast Canada (Northeast)}

415 While the vast majority of previous studies have examined future projections for snow

416 over western NA, snow is also important over the Northeast (Fig. 1a). In this region, heavy

417 snowfall and snow loads are hazards for transportation and building infrastructures and snowmelt

418 plays a key role in spring flooding. The Northeast region is also home to over 180 ski resorts 
419 (https://www.skicentral.com/). Lake effect snow may play a role in driving SWE amounts in this

420 region, but this is likely not captured by any of the models used in this study.

421 As in the previously examined regions, the spread across the MObs ensemble is

422 substantial over the Northeast (Fig. 6c). There is also disagreement on whether SM peaks in

423 February or March over the region. Compared to the MObs the spread in both the CMIP5

424 ensembles is larger than the estimated observed spread, with the ensemble mean values falling in 425 the middle of the MObs (Fig. 6c, SI Figs. S59-S60). The spread across the NA-CORDEX RCMs 426 is smaller than the MObs, with the RCMs following the upper end of the Mobs (Fig. 6f). It is

427 possible that all of the MObs underestimate SWE in the region, as observations are limited.

428 Substantial losses are projected for the region in all of the models (Fig. 6 j-m; individual 429 model results SI Figs. S59-S60). Percent losses are largest October-November and April-May, 430 and smaller in the middle of winter. However, even in winter, most models project that the 431 region will lose more than $40 \%$ of its total SM. The uncertainty range for SM losses is twice as 432 large in the CMIP5-All ensemble than the CMIP5-Driver ensemble, again suggesting CMIP5433 Driver models may not capture the full range of climate possibilities. Regional scale losses are 434 nearly identical in the two NA-CORDEX ensembles. The uncertainty of the change in the 435 RCMs is smaller than the CMIP5-All ensemble, but larger than the CMIP5-Driver ensemble. 436 At first glance, the spatial representation of winter SWE in the CMIP5-Driver and NA437 CORDEX RCM ensembles appears to be very similar, with higher values in the Northeast 438 portion of the region, and lower values to the Southwest (Fig. 10, d-f; SI Figs. 61-69). However, 439 an examination of the spatial details and comparison with topography highlights that even 440 though topographic variations are less extreme in this region than in the IMW, mountains still 441 play a role in driving SWE patterns (e.g. Adirondack Mountains in New York). 
The broad spatial patterns of SWE changes for the end of the century are similar across

443 the ensembles, with larger total losses to the northeast and smaller total losses to the south and

444 larger percent losses over the southern portion of the domain and smaller relative losses over the

445 north. However at closer inspection we see that snow losses are smaller with increasing

446 elevation and higher resolution, indicating topography also dampens snow losses here

\section{4. Summary and Discussion}

RCM ensembles like NA-CORDEX are widely used by scientists and stakeholders across

449 multiple fields. While a plethora of studies have examined temperature and precipitation

450 changes, far fewer have examined critical variables such as snow. In this study we performed a

451 side-by-side comparison of historical and future snow over NA between the NA-CORDEX

452 dynamically downscaled $0.5^{\circ}$ and $0.25^{\circ}$ RCM simulations and their driving GCMs $\left(1.25^{\circ}-2.8^{\circ}\right)$.

453 The primary goals of this study were to evaluate model performance and examine how end-of-

454 century projections for snow differ between the different resolution ensembles.

455 To evaluate model performance, we used an ensemble of observationally constrained

456 SWE datasets. We demonstrate that the uncertainty in gridded snow datasets is large, even

457 across datasets with high resolutions. This uncertainty is associated with difficulties in

458 measuring snow and is a major challenge for the snow science community. Our analysis also

459 shows that GLDAS-noah is a considerable outlier from the other MObs and consistently has the

460 lowest values for all snow metrics.

461 In their historical climate simulations, the CMIP5-Driver and CMIP5-ALL ensembles

462 underestimate NA SCE (excluding GLDAS-noah from the MObs) while both NA-CORDEX

463 ensembles tend to follow the higher end of the MObs. Simulated biases in SCE can have an

464 impact on the radiation budget thereby influencing surface temperatures and weather patterns 
465 (citations). On average the CMIP5-Driver ensemble underestimates AM-SWE and SCD over

466 eastern Canada and at high elevations, but overestimate them everywhere else. In both RCMs,

467 AM-SWE and SCD are positive everywhere except the highest elevations and small areas over

468 Canada. While the $0.25^{\circ}$ simulations have greater spatial details and higher mountains than the

$4690.5^{\circ}$ models, the spatial pattern of SWE and the magnitude of the biases are similar between the

470 ensembles. Over the three regions examined, the spread in historical SM is greater across the

471 GCM ensembles than the RCM ensembles, especially in the IMW and Northeast regions.

472 End-of-century projections for snow over NA are broadly similar across the ensembles

473 considered. In all ensembles, SCE, AM-SWE, and SCD are projected to decrease over most of

474 NA, with the exception of increases in AM-SWE at high-latitudes. In terms of magnitude, the

475 largest losses in AM-SWE and SCD occur over the mountains in the western half of the domain

476 and over coastal-eastern Canada. However, percent losses in AM-SWE are largest at low-

477 elevations and low-latitude regions. Comparison of these ensembles shows that in terms of

478 percent change, which can be more useful in the application of climate model data to climate

479 change impacts, the CMIP5 GCMs tend to project a more severe picture of total snow loss for

480 NA. For example, the CMIP5-Driver ensemble project that just over half of NA will experience

481 greater than 50\% losses in AM-SWE, while the RCMs that only 36-38\% of NA will experience

482 greater than $50 \%$ losses in AM-SWE. These differences are likely largely related to the poor

483 representation of topography in the GCMs, but are also related to differences in baseline snow

484 amounts (see more below).

485 While the large-scale picture of future changes in snow are similar between the

486 ensembles, zooming in on individual regions helps highlight where differences between the

487 ensembles occur. Over the IMW and Northeast regions, percent SM losses are larger in the 
488 GCMs than the RCMs, while over NC-Canada percent increases in winter SM are smaller in the 489 GCMs. The uncertainty in these future changes is larger in the CMIP5-Driver GCMs than the 490 RCM ensembles over the IMW and NC-Canada, but smaller in the Northeast region. While SM 491 is projected to decrease during all months of the year in all of the models over the IMW and 492 Northeast region, 70\% of the models examined show winter SM increasing over NC-Canada.

493 The largest differences across the ensembles are found over the IMW region where topography 494 plays a large role driving snowfall and SWE amounts through orographic enhancement of 495 precipitation and lower temperatures. As the GCMs oversample low-to-middle elevations and 496 under-sample the higher elevations, historical SM is under-represent at most elevations, percent 497 snow losses are larger in the GCMs than the RCMs at most elevations, and the GCMs have no 498 information about snow at the higher elevations. Our results suggest that a that a more accurate 499 representation of snow (especially at high elevations) allows for the buffering of snow losses, 500 which we don't see in coarse models. In contrast to the IMW, over NC-Canada the GCM and 501 RCM ensembles also show the greatest agreement in historical SM and percent SM changes in 502 this region, which we suspect could be due to the lack of significant topographic features in the 503 region.

504 Overall, while we find interesting differences in the specific regional details between the 505 between the CMIP5-Driver GCMs and the NA-CORDEX RCMs, we do not see significant 506 differences between two NA-CORDEX ensembles. The largest differences between the GCMs 507 and RCMs are found in regions of complex topography, but even over the IMW the two RCM 508 ensembles have very similar climate change responses. So while the spatial details of snow are 509 more refined in the $0.25^{\circ}$ ensemble, the overall impact to regional snow is small. However, as 510 shown in Walton et al (2021), fine-scale details associated with snow in the mountainous may be 
511 important for end-users who statistically downscale temperature from climate models, as

512 incorrectly capturing snow to no-snow transitions in the future can result in the incorrect

513 amplification of surface temperatures associated with the snow albedo feedback.

514 While these results are similar to other studies which have examined snow over NA (e.g.

515 McCrary and Mearns, 2019; Rasmussen et al. 2011). Our study highlights that the severity of

516 future changes in snow, their uncertainties, and regional details are a function of the size and

517 configuration of the model simulations/ensembles examined and the resolution of the

518 simulations. The result that the GCMs tend to project a more severe picture of relative snow

519 losses, in part because they have fewer high-elevation points, is important to remember when

520 considering studies such as Diffenbaugh et al (2012), which used the CMIP5 models to assess

521 hydrologic extremes and water availability over regions of the Northern Hemisphere, including

522 the western US.

523 There are also a few notable limitations to this study. First, while our focus has been on

524 how increases in resolution impacts the representation of historical and future snow over NA and

525 their uncertainties, the NA-CORDEX- $0.5^{\circ}$ and NA-CORDEX- $0.25^{\circ}$ ensembles consist of

526 different combinations of RCM/GCM pairs. These differences in ensemble configuration may

527 also contribute to the differences we found in this study. As discussed in McGinnis and Mearns

528 (2021), funding was extremely limited for NA-CORDEX and the choice of simulations included

529 in the experiment was opportunistic and required leveraging other modeling activities (McGinnis

530 and Mearns, 2021). While the archive consists of simulations with available SWE from 5 RCMs

531 driven with boundary conditions from 7 GCMs with simulations performed at 2 resolutions

532 (Table 2), the simulation matrix itself is both sparse and unbalanced, limiting our ability to dive

533 deeply into the different roles the choice of RCM, GCM, or resolution have on climate change 
534 uncertainty. In this work we chose to include all available ensemble members to highlight the

535 differences in the available datasets that end users may consider. In SI Section 16, we compare

536 results from using the full ensemble with the 7 simulations that have matching RCM/GCM pairs

537 and both resolutions. We find the uncertainty in the historical simulations to be lower in the

538 smaller subset of models, but that the projections of future change and their uncertainties for all

539 snow variables are similar between the full and subset ensembles.

540 Second, while the NA-CORDEX simulations are higher resolution than their GCM

541 counterparts, they are still relatively coarse for capturing precipitation, snowfall, and SWE

542 especially in topographically complex areas. Many of the sectors discussed in the introduction

543 require very high resolution data to study the impacts of future changes in snow. Statistical

544 downscaling techniques are often employed to get at very high-resolution climate information,

545 but this can break the coupling between the atmosphere and the land-surface leading to

546 inconsistent results especially in snow dominated regions (Walton et al, 2021).

547 Past RCM studies have found that resolutions of 4-6km to be necessary to match in-situ

548 point observations of precipitation, snowfall, and SWE (Garvert et al, 2007; Rasmussen et al,

549 2011). The argument for this is that terrain-induced convection and local air circulation patterns

550 associated with smaller ridges and valleys that are important for snowfall patterns are better

551 resolved, and surface temperatures are better represented. Wind redistribution of snow is also

552 important, which is also not captured in many models (Musselman et al, 2015). Many high-

553 resolution modeling studies have examined changes in snow over regions of NA (e.g. Sun et al,

554 2019; Rasmussen et al, 2011; Musselman et al, 2017). While these studies have been able to

555 look at detailed process level changes that are important, they have been limited in either domain

556 size or by the use of only one RCM or one GCM, limiting the examination of uncertainty. As 
557 computing power, storage, and analysis of big data continues to advance, we expect larger

558 ensembles convection permitting simulations (CPSs) over larger domains. The coordination of

559 regional CPSs is ongoing over Europe in one CORDEX Flagship Pilot Study (Coppola et al,

560 2020), but such studies are not being coordinated over NA yet. Until that time, NA-CORDEX

561 fills a need in the community as it provides spatially uniform, higher resolution simulations with

562 enough model diversity to explore uncertainty while covering a large enough domain to be useful

563 for many regional interests and are adequate for efforts such as the US National Climate

564 Assessment and the IPCC.

\section{Acknowledgements}

566 The authors acknowledge Ross Brown and the two anonymous reviewers for their constructive

567 feedback. This work was supported by the DoE Regional and Global Climate Modeling program

568 via grants DE-SC0016438 and DE-SC0016605 and the NCAR Regional Climate Uncertainty

569 Program managed by Dr. Mearns, funded by NSF under the NCAR cooperative agreement. We

570 acknowledge the WCRP's Working Group on Coupled Modelling and the CMIP5 modeling

571 groups for producing and making available their model output. We also acknowledge high-

572 performance computing support provided by NCAR's CISL (Computational and Information

573 Systems Laboratory 2017), and NCL (The NCAR Command Language 2019). NCAR is

574 sponsored by the NSF. Livneh data was provided by NOAA/OAR/ESRL PSL. The CRCM5-O

575 data has been generated and supplied by Ouranos.

576

577

578

579 


\section{Declarations}

581 Funding: This work was supported by DoE Regional and Global Climate Modeling grant DE-

582 SC0016438 and the NCAR Regional Climate Uncertainty Program managed by Dr. Mearns,

583 funded by NSF under the NCAR cooperative agreement.

584 Conflicts of Interest/Competing Interests: None.

585 Availability of data and material: Snow data from NA-CORDEX will soon be available on

586 NCAR's Climate Data Gateway (https://na-cordex.org/data-access.html) (approximately by

587 October 2021). Until that point, please reach out to rmccrary@ucar.edu for data access. CMIP5

588 Data is available from the WCRP's Earth System Grid Federation Website (https://esgf-

589 node.llnl.gov/projects/cmip5/).

590 Code availability: The code used for this work is available on Rachel McCrary's GitHub

591 account: (https://github.com/mccraryclimo/nacordex_ClimaticChange_Code)

592 Authors' contributions: McCrary: Writing- Original Draft, Conceptualization, Methodology,

593 Formal Analysis, Visualization. Mearns: Conceptualization, Supervision, Funding acquisition,

594 Writing - Review \& Editing. Hughes: Writing - Review \& Editing. Biner: Investigation (model

595 simulations), Writing - Review \& Editing. Bukovsky: Investigation (model simulations), Writing

596 - Review \& Editing

597

598

599

600

601

602 


\section{References}

605 Barnett, T. P., J. C. Adam, and D. P. Lettenmaier (2005) Potential impacts of a warming climate on water availability in snow-dominated regions. Nature, 438:303-309.

607 Barsugli, J. J., et al. (2020). Projections of mountain snowpack loss for wolverine denning elevations in the Rocky Mountains. Earth's Future, 8.

609

Beaudoing, H. and M. Rodell, NASA/GSFC/HSL (2020), GLDAS Noah Land Surface Model L4 3 hourly 0.25 x 0.25 degree V2.1, GES DISC, Accessed: 06-10-2019 10.5067/E7TYRXPJKWOQ

612 Berghuijs, W. R., et al. (2016) Dominant flood generating mechanisms across the United States. GRL, 43:4382-4390.

614 Brown, R. D., and P. W. Mote (2009) The Response of Northern Hemisphere Snow Cover to a 615 Changing Climate. J. Climate, 22:2124-2145.

616 Brown, R. D. and B. Brasnett (2010) updated annually. Canadian Meteorological Centre (CMC)

617 Daily Snow Depth Analysis Data, Version 1. Boulder, Colorado USA. NASA National 618 Snow and Ice Data Center Distributed Active Archive Center. doi: https://doi.org/10.5067/W9FOYWH0EQZ3. Accessed: 15-03-2021.

620 Broxton, P., X. Zeng, and N. Dawson (2019) Daily 4 km Gridded SWE and Snow Depth from Assimilated In-Situ and Modeled Data over the Conterminous US, Version 1. NASA NSIDC. Accessed: 19-06-2020.

623 Burakowski, E. and M. Magnusson (2012) Climate Impacts on the Winter Tourism Economy in 624 the United States. National Resources Defense Council, 36 pp. 
625 Campbell, C., et al. (2007) Current and Future Snow Avalanche Threats and Mitigation

626 Measures in Canada. Canadian Avalanche Center report prepared for Public Safety

$627 \quad$ Canada.

628 Campbell, J. L., et al. (2005) Winter in northeastern North America: A critical period for 629 ecological processes. Front. Ecol. Environ., 3, 314-322.

630 Chin, N., et al. (2018) Assessing potential winter weather response to climate change and 631 implications for tourism in the US Great Lakes and Midwest. J. Hydrology: Regional

633 Christensen, N. S., and Lettenmaier, D. P. (2007). A multimodel ensemble approach to assessment of climate change impacts on the hydrology and water resources of the

Diffenbaugh, N. S., M. Scherer, and M. Ashfaq (2012) Response of snow-dependent hydrologic extremes to continued global warming. Nature Climate Change 3:379-384.

ETOPO5 (1988) Data Announcement 88-MGG-02, Digital relief of the Surface of the Earth. NOAA, National Geophysical Data Center, Boulder, Colorado.

640 Garvert, M. F., , B. Smull, , and C. Mass, 2007: Multiscale mountain waves influencing a major orographic precipitation event. J. Atmos. Sci., 64, 711-737.

642 Harpold, A. A. (2016) Diverging sensitivity of soil water stress to changing snowmelt timing in 643 the Western U.S. Adv.Water Res., 92:16-129.

644 Henn, B., et al. (2018) An assessment of differences in gridded precipitation datasets in complex terrain. J. Hydro., 556:1205-1219.

646 Hughes, M. et al, (2021) Cool season precipitation projections for California and the Western

647 United States in NA-CORDEX models. Clim Dynamics, 56, 3081-3102. 
648 Jeong, D. I., and L. Sushama (2018) Projected changes to extreme wind and snow environmental 649 loads for buildings and infrastructure across Canada. Sustainable Cities and Society, $36: 225-236$.

651 Krasting, J. P., et al., (2013) Future changes in Northern Hemisphere snowfall. J. Climate, $652 \quad 26: 7813-7828$.

653 Livneh, B., et al. (2010) Noah LSM Snow Model Diagnostics and Enhancements. $J$. $654 \quad$ Hydrometeor., 11:721-738.

655 Livneh B., et al. , 2013: A Long-Term Hydrologically Based Dataset of Land Surface Fluxes and 656 States for the Conterminous United States: Update and Extensions, Journal of Climate, $657 \quad 26,9384-9392$.

658 Luojus, Kari, et al., 2020: GlobSnow v3.0 snow water equivalent (SWE). PANGAEA. 659 https://doi.org/10.1594/PANGAEA.911944

660 Lundquist, J., et al. (2020) Our Skill in Modeling Mountain Rain and Snow is Bypassing the 661 Skill of Our Observational Networks. BAMS 100: 2473-2490.

662 Mahoney, K. et al. (2021) Precipitation Projections for California and the Western United States 663 in NA-CORDEX models. Climate Dynm., 56, 3081-3102.

664 Markhoff, M.S. and A.C. Cullen (2008) Impact of climate change on Pacific Northwest 665 hydropower. Climatic Change, 87:451-469.

666 McCrary, R.R., S. McGinnis, and L.O. Mearns (2017) Evaluation of Snow Water Equivalent in 667 NARCCAP Simulations, Including Measures of Observational Uncertainty. J. Hydromet., 668 18: 
McCrary, R. R., and L. O. Mearns (2019) Quantifying and Diagnosing Sources of Uncertainty in Midcentury Changes in North American Snowpack from NARCCAP. J. Hydromet. 20: $2229-2252$.

672 McGinnis, S. and. L. Mearns (2021) Building a climate service for North America based on the NA-CORDEX data archive. Climate Services, 22, 100233.

674 Mearns, L.O., et al. (2015) Uses of Results of Regional Climate Model Experiments for Impacts and Adaptation Studies: the Example of NARCCAP. Curr Clim Change Rep, 1, 1-9.

Mearns, L.O., et al. (2017) The NA-CORDEX dataset, version 1.0. NCAR Climate Data Gateway, Boulder CO, Accessed: 01-06-2020.

Mekis, E., et al. (2018) An Overview of Surface-Based Precipitation Observations at Environment and Climate Change Canada, Atmosphere-Ocean, 56:2, 71-95,.

Minder, J.R., Letcher, T. W., and Skiles, S. M. (2016) An evaluation of high-resolution regional climate model simulations of snow cover and albedo over the Rocky Mountains, with implications for the simulated snow-albedo feedback, J. Geophys. Res. Atmos. 121: 9069-9088.

Mudryk, L., et al. (2020) Historical Northern Hemisphere snow cover trends and projected changes in the CMIP6 multi-model ensemble. The Cryosphere 14:2495-2514.

Muñoz-Sabater, J., (2019): ERA5-Land hourly data from 1981 to present. Copernicus Climate Change Service (C3S) Climate Data Store (CDS). Accessed:10-06-2020), 10.24381/cds.e2161bac

Musselman et al. (2015) Impact of windflow calculations on simulations of alpine snow accumulation, redistribution and ablation, Hydro. Processes, 29(18) 3983-3999. 
691 Musselman et al, (2017) Slower snowmelt in a warmer world. Nature Climate Change. 7, 214692 219.

693 NOHRSC, 2004: Snow Data Assimilation System (SNODAS) Data Products at NSIDC, Version

694 1. NSIDC. Accessed: 12-06-2019.

695 Notaro, M., et al. (2014) Twenty-first-century projections of snowfall and winter severity across 696 central-eastern North America. J. Climate 27:6526-6550.

697 Palko, K. and Lemmen, D.S. (Eds.). (2017). Climate risks and adaptation practices for the 698 Canadian transportation sector 2016. Ottawa, ON: Government of Canada.

699 Qin, Y et al. (2020) Agricultural risks from changing snowmelt. Nat. Clim. Chang. 10:459-465.

700 Räisänen, J. (2008) Warmer climate: less or more snow? Climate Dynamics, 30: 307-319.

701 Rasmussen, R., et al. (2011) High-Resolution Coupled Climate Runoff Simulations of Seasonal 702 Snowfall over Colorado: A Process Study of Current and Warmer Climate. J.Climate $703 \quad 24: 3015-3048$.

704 Rhoades, A. M., A. D. Jones, and P. A. Ullrich, 2018a: The Changing Character of the California 705 Sierra Nevada as a Natural Reservoir. $G R L, 45,13,008-13,019$.

706 Rhoades, A. M., P. A. Ullrich, and C. M. Zarzycki, 2018b: Projecting 21st century snowpack 707 trends in western USA mountains using variable-resolution CESM. Clim Dyn, 50, 261$708 \quad 288$.

709 Sun et al. (2018) Understanding End-of-Century Snowpack Changes over California's Sierra $710 \quad$ Nevada. GRL. 46(2). 933-943.

711 Taylor, K. E., R. J. Stouffer, and G. A. Meehl (2012) An Overview of CMIP5 and the 712 Experiment Design. BAMS 93:485-498. 
713 U.S. National Ice Center. 2008, updated daily. IMS Daily Northern Hemisphere Snow and Ice

714 Analysis at $1 \mathrm{~km}, 4 \mathrm{~km}$, and $24 \mathrm{~km}$ Resolutions, Version 1. [1997-2010]. Boulder,

715 Colorado USA. NSIDC: National Snow and Ice Data Center.

716 doi: https://doi.org/10.7265/N52R3PMC.

717 Vavrus, S. (2007) The role of terrestrial snow cover in the climate system. Climate Dynamics, $718 \quad 29: 73-88$.

719 Walton, D et al. (2021) Understanding Differences in California Climate Change Projections 720 Produced by Dynamical and Statistical Downscaling. JGR Atmo., 125(10).

721 Westerling, A. L. et al. (2006) Warming and Earlier Spring Increase Western U.S. Forest 722 Wildfire Activity. Science, 313:940-943.

723 Wobus, C. et al., (2017) Projected climate change impacts on skiing and snowmobiling: A case 724 study of the United States. Global Environmental Change, 45:1-14, 725 doi:10.1016/j.gloenvcha.2017.04.006.q

726 Xia, Y., et al., NCEP/EMC (2012), NLDAS Noah Land Surface Model L4 Hourly 0.125 x 0.125

727 degree V002, Edited by David Mocko, NASA/GSFC/HSL, GES DISC, Accessed: [10-

728 06-2019], 10.5067/47Z13FNQODKV

729

730

731

732

733

734

735 


\section{Tables}

737 Table 1. The NA-CORDEX RCMs and their driving CMIP5 GCMs examined in this

738 study. Each column displays the resolution $\left(0.44^{\circ}\right.$ or $50 \mathrm{~km} ; 0.22^{\circ}$ or $\left.25 \mathrm{~km}\right)$ of the RCM

739 simulations or the resolution of the driving GCM. Snow is not available from the EC-EARTH

740 GCM simulation, but is available from the HIRHAM5 RCM driven with EC-EARTH boundary

741 conditions.

742

\begin{tabular}{|l|c|l|l|l|c|c|}
\hline GCM/RCM & CanRCM4 & $\begin{array}{l}\text { CRCM5- } \\
\text { U }\end{array}$ & $\begin{array}{l}\text { CRCM5- } \\
\text { O }\end{array}$ & WRF & HIRHAM5 & $\begin{array}{l}\text { GCM } \\
\text { Resolution }\end{array}$ \\
\hline $\begin{array}{l}\text { HadGEM2- } \\
\text { ES }\end{array}$ & - & - & - & $50 \mathrm{~km} / 25 \mathrm{~km}$ & - & $1.25 \times 1.875^{\circ}$ \\
\hline CanESM2 & $0.44^{\circ} / 0.22^{\circ}$ & $0.44^{\circ} / 0.22^{\circ}$ & $-/ 0.22^{\circ}$ & - & - & $\sim 2.8^{\circ} \mathrm{x} \sim 2.8^{\circ}$ \\
\hline CNRM-CM5 & - & - & $-/ 0.22^{\circ}$ & - & - & $\sim 1.4^{\circ} \mathrm{x} \sim 1.4^{\circ}$ \\
\hline $\begin{array}{l}\text { MPI-ESM-LR } \\
\text { MPI-ESM- } \\
\text { MR }\end{array}$ & - & $0.44^{\circ} / 0.22^{\circ}$ & $-/ 0.22^{\circ}$ & $50 \mathrm{~km} / 25 \mathrm{~km}$ & - & $\sim 1.87^{\circ} \mathrm{x} \sim 1.87$ \\
\hline EC-EARTH & - & $0.44^{\circ} 0 / .22^{\circ}$ & - & - & - & $\sim 1.87^{\circ} \mathrm{x} \sim 1.87$ \\
\hline $\begin{array}{l}\text { GFDL- } \\
\text { ESM2M }\end{array}$ & - & - & $-/ 0.22^{\circ}$ & $50 \mathrm{~km} / 25 \mathrm{~km}$ & - & $\sim 2.0^{\circ} \mathrm{x} 2.5^{\circ}$ \\
\hline
\end{tabular}


749 Table 2. Table of model-informed observational datasets (MObs) used in this study.

\begin{tabular}{|l|l|l|l|l|l|}
\hline Product & Resolution & Domain & Frequency & Time Period & Reference \\
\hline SNODAS & $1 \mathrm{~km}$ & CONUS & Daily & $2003-2020$ & NOHRSC (2004) \\
\hline UA-SWE & $4 \mathrm{~km}$ & CONUS & Daily & $1981-2020$ & Broxton et al. (2019) \\
\hline Livneh & $0.0625^{\circ}(\sim 6 \mathrm{~km})$ & CONUS & Daily & $1950-2013$ & Livneh et al. (2015) \\
\hline $\begin{array}{l}\text { ERA5- } \\
\text { land }\end{array}$ & $0.1^{\circ}(\sim 9 \mathrm{~km})$ & Global & Hourly & $1981-2020$ & Munoz-Sabater (2019) \\
\hline $\begin{array}{l}\text { NLDAS- } \\
\text { noah }\end{array}$ & $0.125^{\circ}(\sim 13 \mathrm{~km})$ & CONUS & 3 -hourly & $1979-2020$ & Xia et al. (2012) \\
\hline $\begin{array}{l}\text { NLDAS- } \\
\text { vic }\end{array}$ & $0.125^{\circ}(\sim 13 \mathrm{~km})$ & CONUS & 3 -hourly & $1979-2020$ & Xia et al. (2012) \\
\hline $\begin{array}{l}\text { GLDAS- } \\
\text { noah }\end{array}$ & $0.25^{\circ}(\sim 27 \mathrm{~km})$ & Global & 3 -hourly & $1948-2013$ & Beaudoing (2019) \\
\hline $\begin{array}{l}\text { GlobSnow } \\
\text { v.3 }\end{array}$ & $25 \mathrm{~km}$ & N. Hemisphere & Daily & $1979-2020$ & Luojus et al. (2020) \\
\hline $\begin{array}{l}\text { CMC } \\
\text { CMn }\end{array}$ & $24 \mathrm{~km}$ & N. America & Monthly & $1998-2020$ & $\begin{array}{l}\text { Brown and Brasnett } \\
\text { (2010) }\end{array}$ \\
\hline
\end{tabular}




\section{Figures}

762

763

764

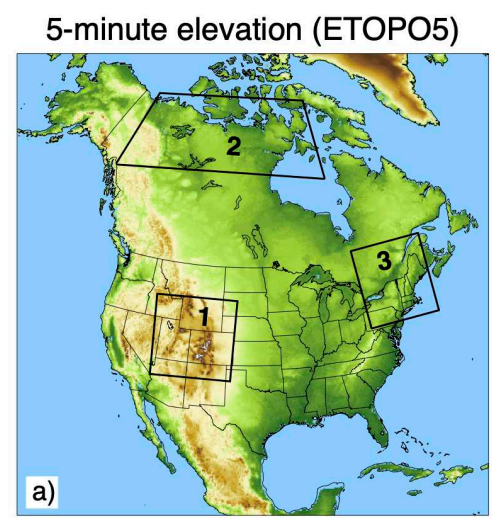

NA-CORDEX $\left(0.5^{\circ}\right)$

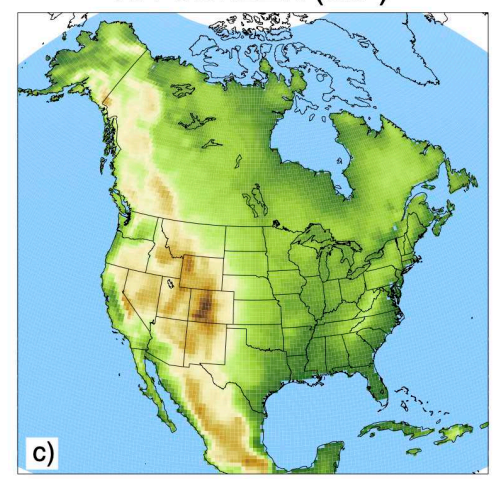

b)

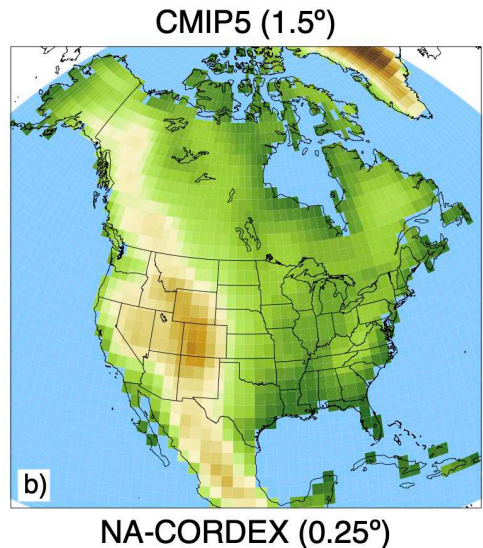

d)

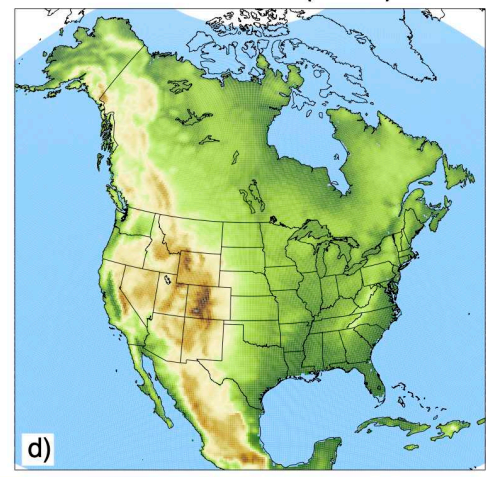

12004507009501200145017001950220024502700295032003450

Fig. 1 Representation of topography from the 5-minute ETOPO5 (1988) topographic dataset (a), the ensemble-average topography from the CMIP5-Driver ensemble (b), the NA-CORDEX-0.5 ensemble (c) and the NA-CORDEX $\left(0.25^{\circ}\right)$ ensemble. The three sub-regions examined are outlined in (a) where (1) is the U.S. Intermountain West, (2) is North-Central Canada, and (3) is the Northeast U.S. and Southeast Canada. 

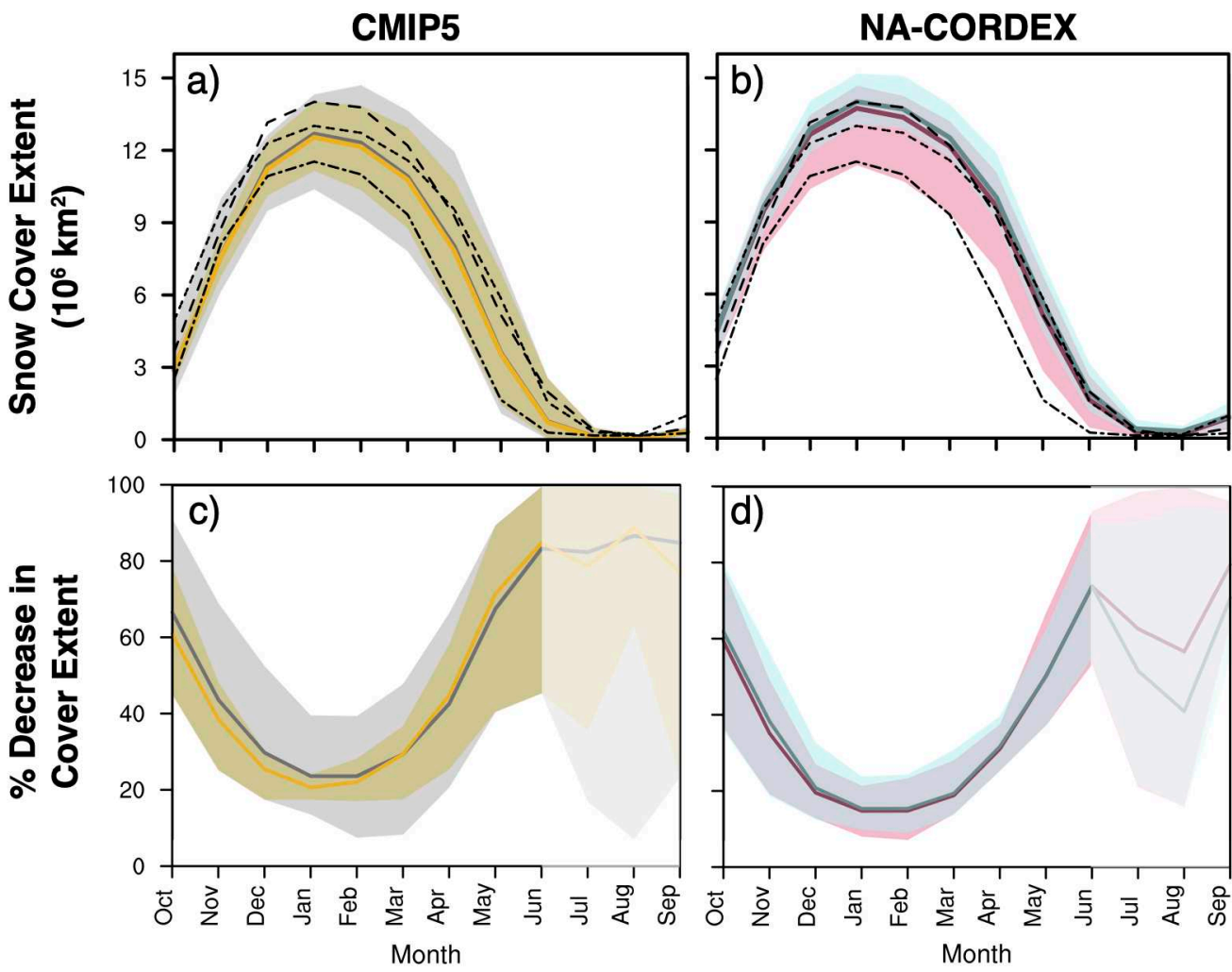

Fig. 2 The annual cycle of monthly mean NA SCE from the MObs (dashed lines on a and b) and the historical climate simulations from the two CMIP5 ensembles (a) and two NA-CORDEX ensembles (b) examined in this study. Also shown is the annual cycle of the percent decrease in NA SCE projected for the end-of-century from the CMIP5 ensembles (c) and the NA-CORDEX ensembles (d). The spread of each ensemble is displayed with colored shading. The average of each ensemble is plotted with a corresponding solid line. Percent decreases in SCE for JulySeptember have been masked as they are skewed by small number division. NA SCE has been calculated using the native grid of all models and datasets. 

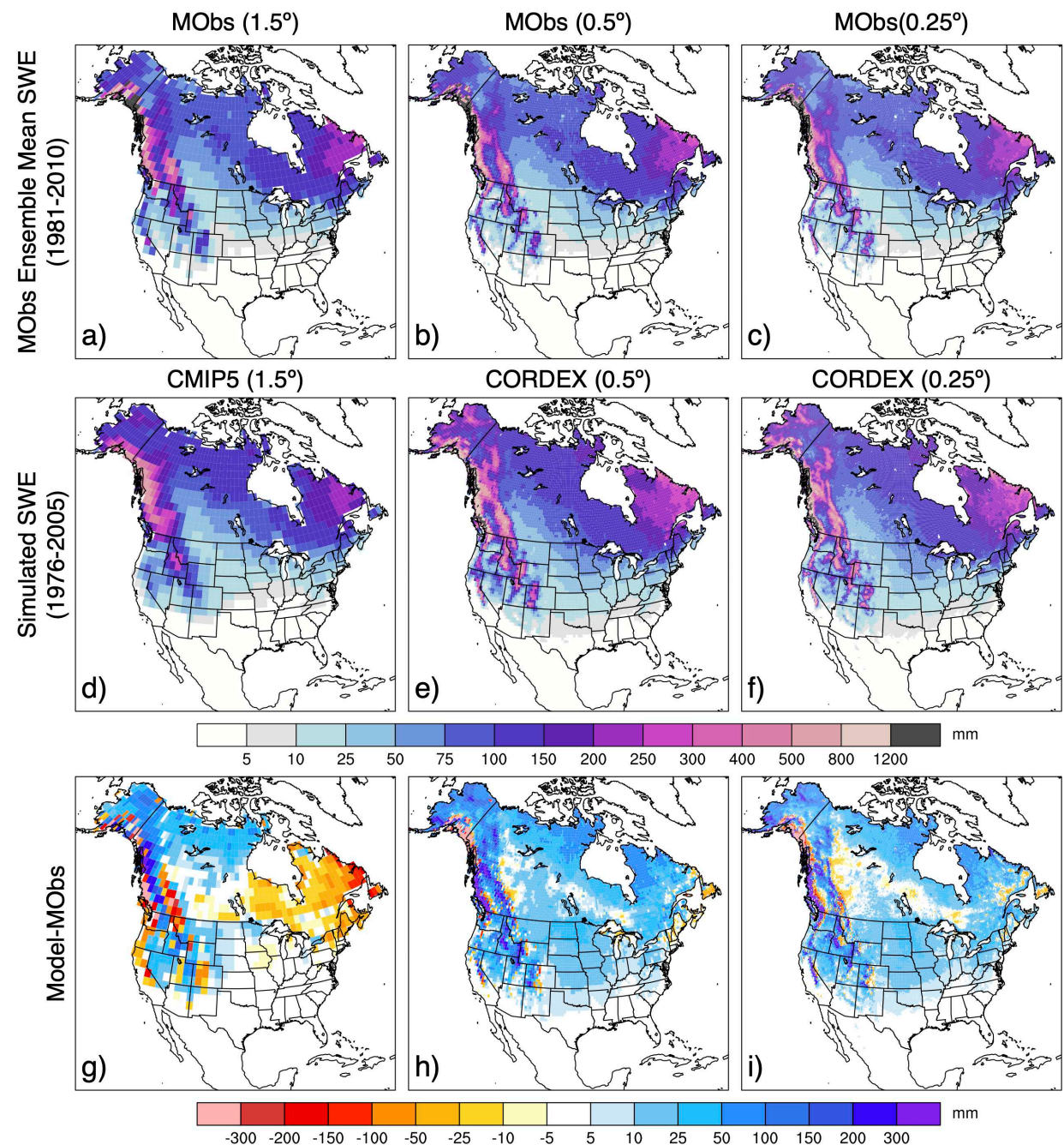

\section{h)}
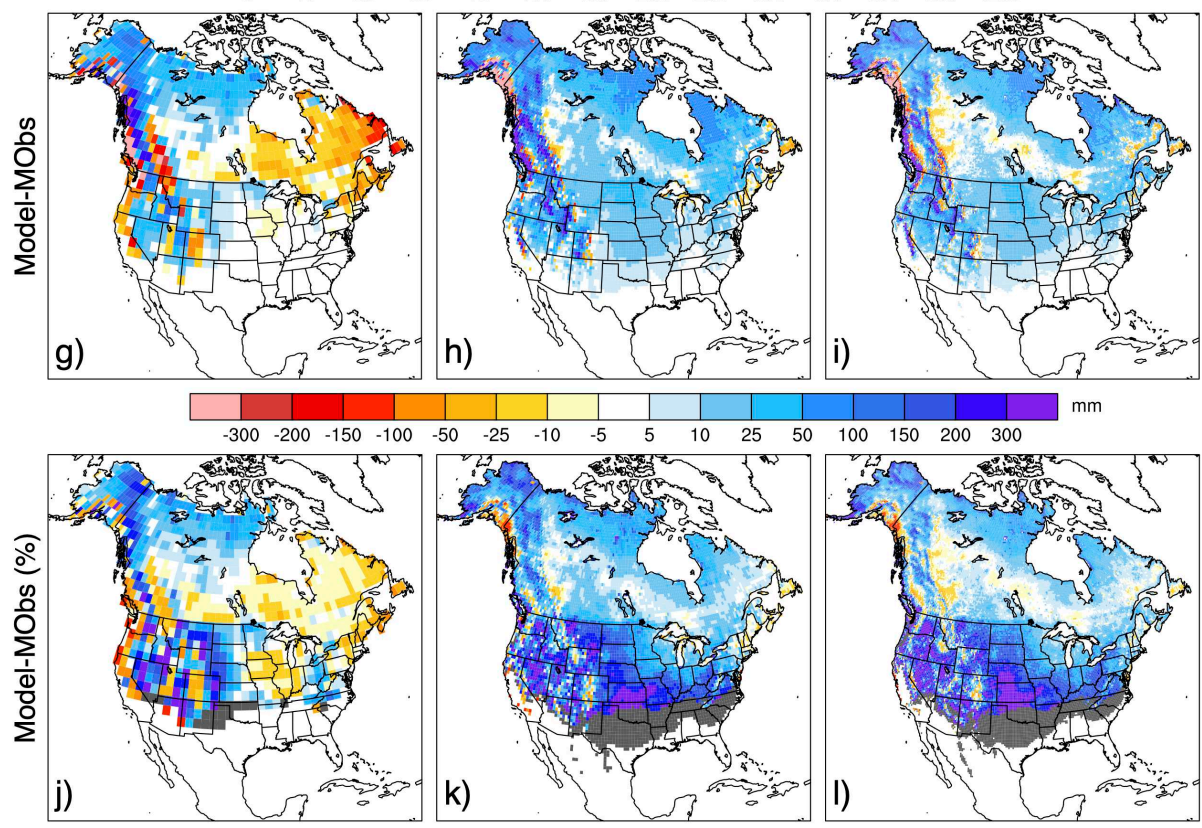

$\begin{array}{llllllllllllllll}-200 & -150 & -100 & -80 & -60 & -40 & -20 & -5 & 5 & 20 & 40 & 60 & 80 & 100 & 150 & 200\end{array}$

Fig. 3 Maps of the average annual monthly maximum SWE (AM-SWE) from the MObs ensemble mean which has been regridded to the common $1.5^{\circ}, 0.5^{\circ}$ and $0.25^{\circ}$ resolution (a-c). Ensemble mean AM-SWE from the historical time period for the three model ensembles (d-f). Also shown are the magnitude (g-i) and percent (j-1) of the simulated bias (model-MObs) of AM-SWE. The MObs ensemble mean is calculated independently at each gridbox using datasets with available data (See SI Figs. S9-S11). 

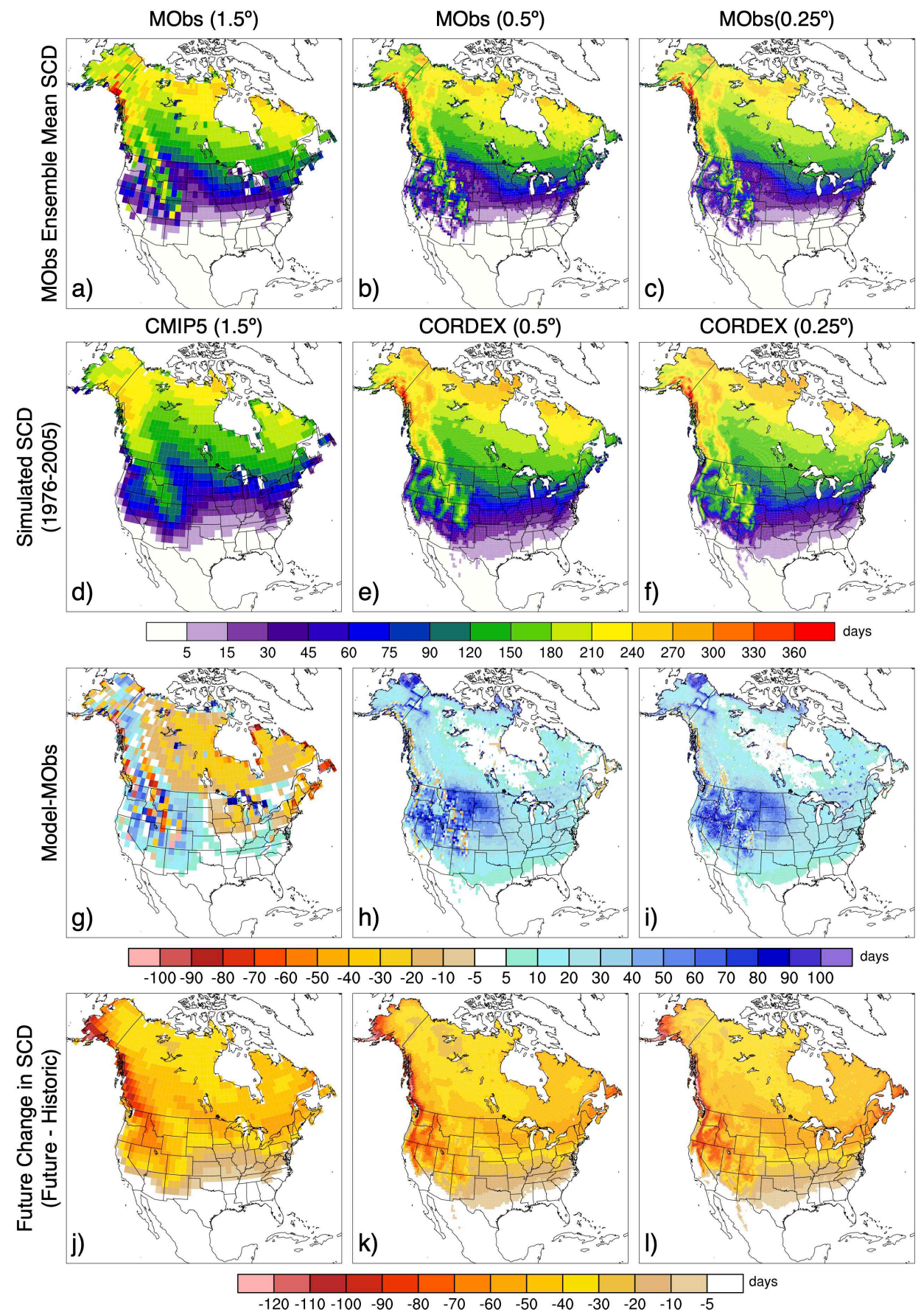

811

812

813

814

815

816

817

818

819

820
Fig. 4 Maps of snow cover duration (SCD) from the MObs ensemble mean regridded to the common $1.5^{\circ}, 0.5^{\circ}$ and $0.25^{\circ}$ grids (a-c), and the ensemble mean SCD from the historical time period from each model ensemble (d-f). Also shown are the simulated bias in SCD (modelMObs, g-i) and the future change in SCD (future-historical, j-1). The MObs ensemble mean is calculated independently at each gridbox using datasets with available data (See SI Figs. S21S23). 

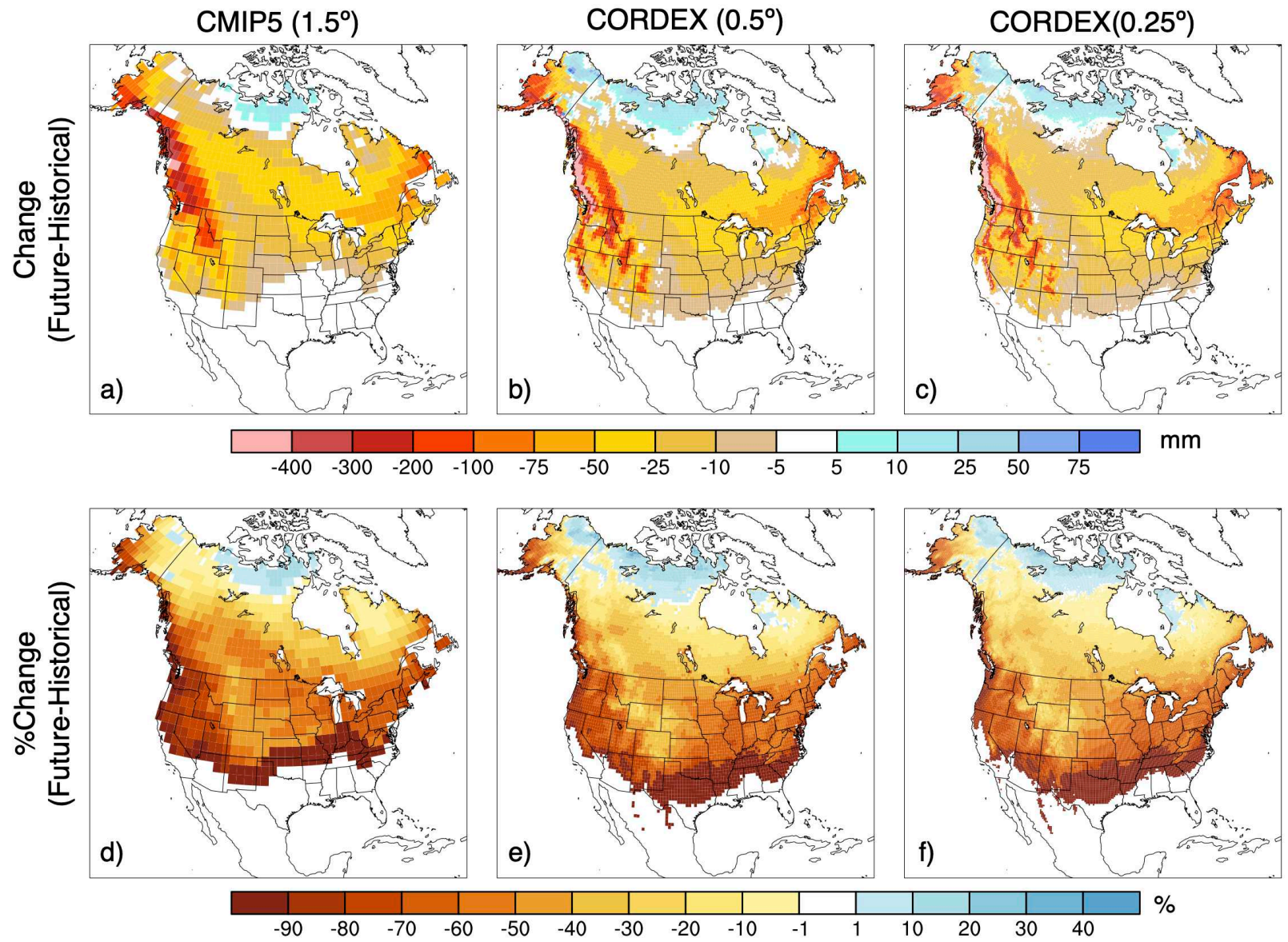

825

826

827

828

Fig. 5 Maps of the magnitude (a-c) and percent (d-f) change in ensemble mean AM-SWE projected by the end-of-the century by the three model ensembles (Future-Historic). 

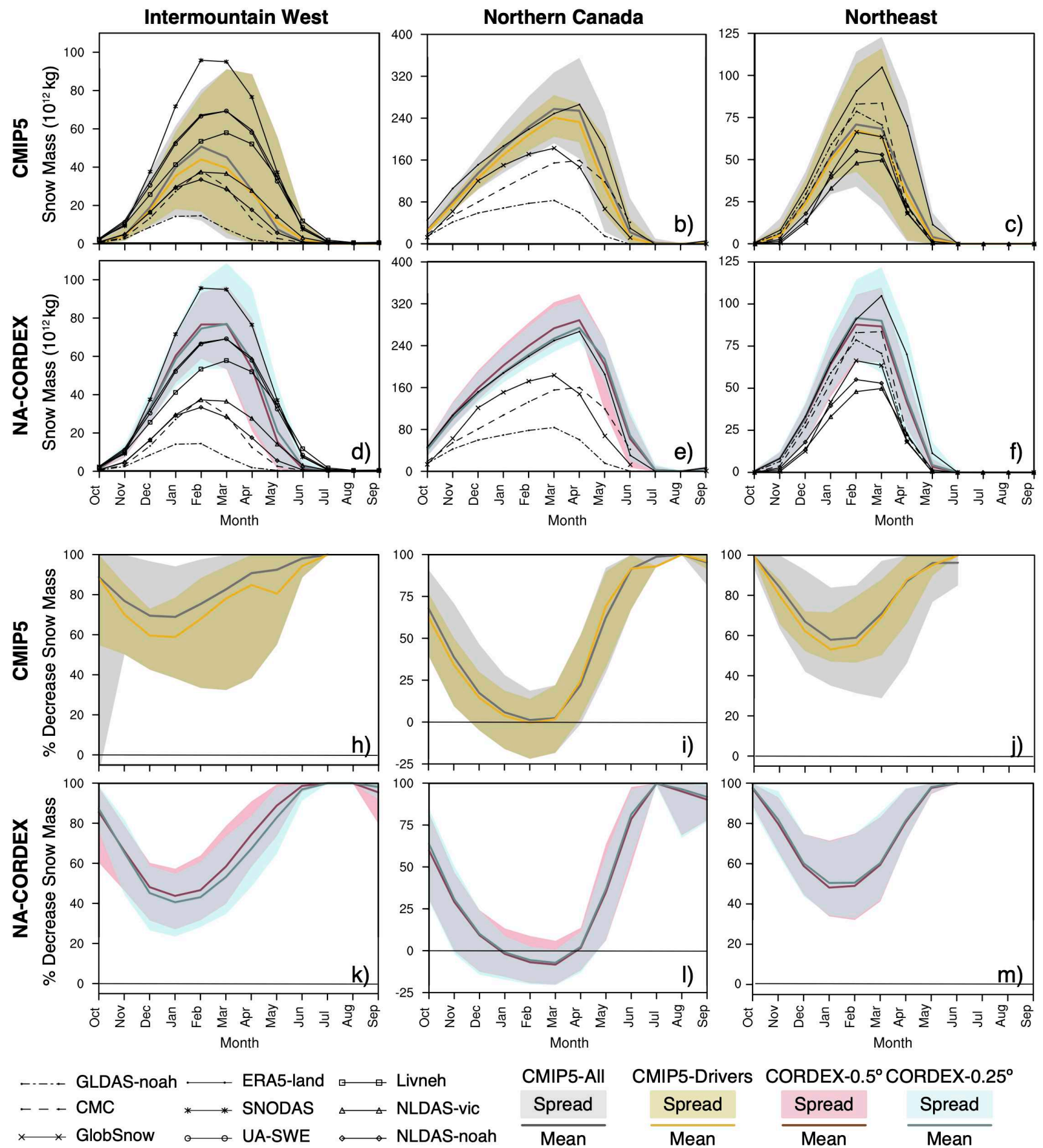

Fig. 6 The first two rows show the annual cycle of SM from the CMIP5-All and CMIP5-Driver ensembles (a-c), the NA-CORDEX ensembles (d-f) and available MObs, for the IMW (a,d), NCCanada $(b, e)$, and Northeast $(c, f)$ regions. The last two rows show the percent decrease SM projected for the end of the century for the CMIP5 (h-j) and NA-CORDEX ensembles (k-m). All regional averages are calculated on each model's native grid. 

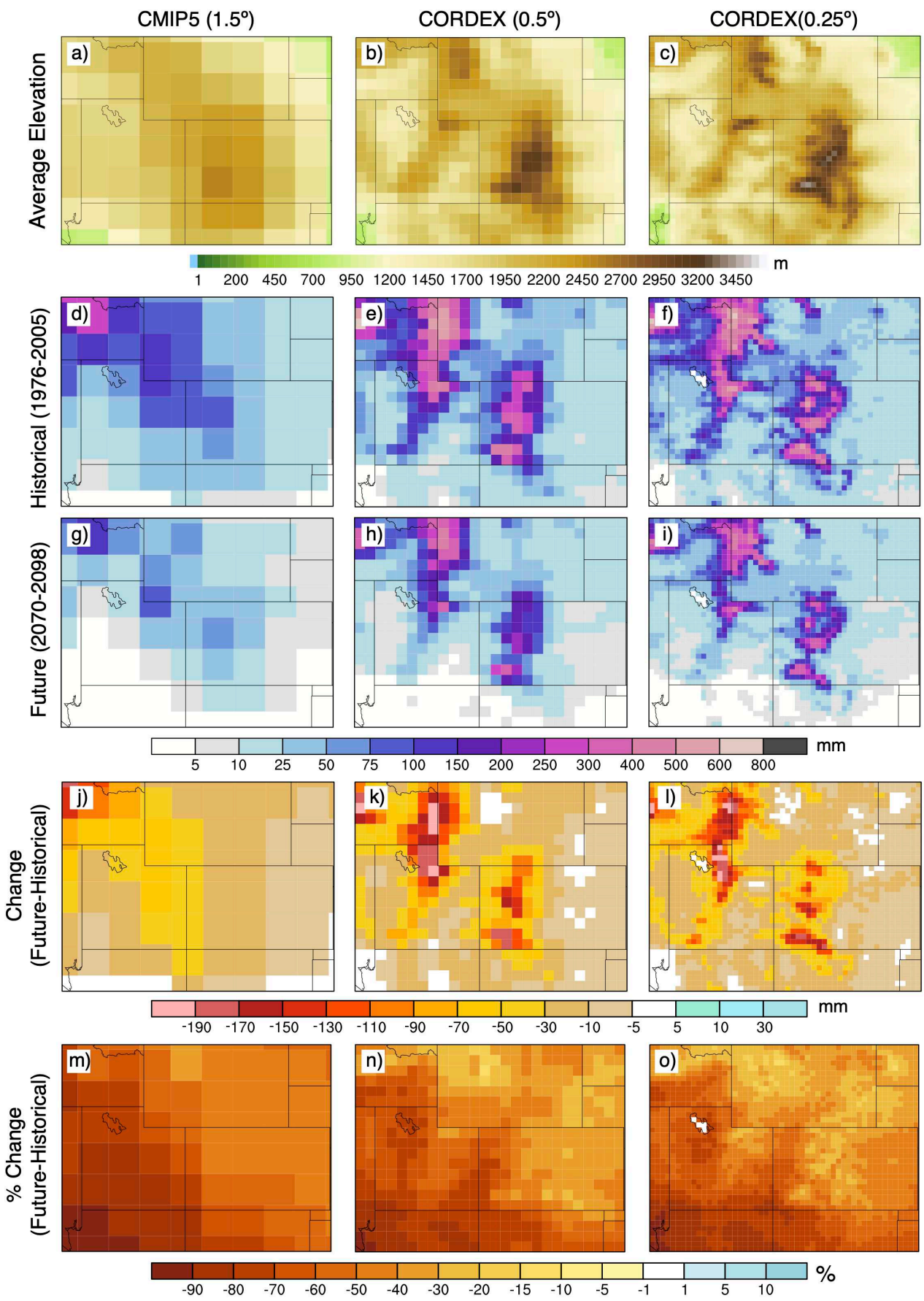

Fig. 7 Maps over the IMW region of the ensemble mean topography (a-c), ensemble mean historic AM-SWE (d-f), ensemble mean future AM-SWE (g-i), and the magnitude (j-1) and percent change (Future-Historic) in AM-SWE from the three model ensembles. 

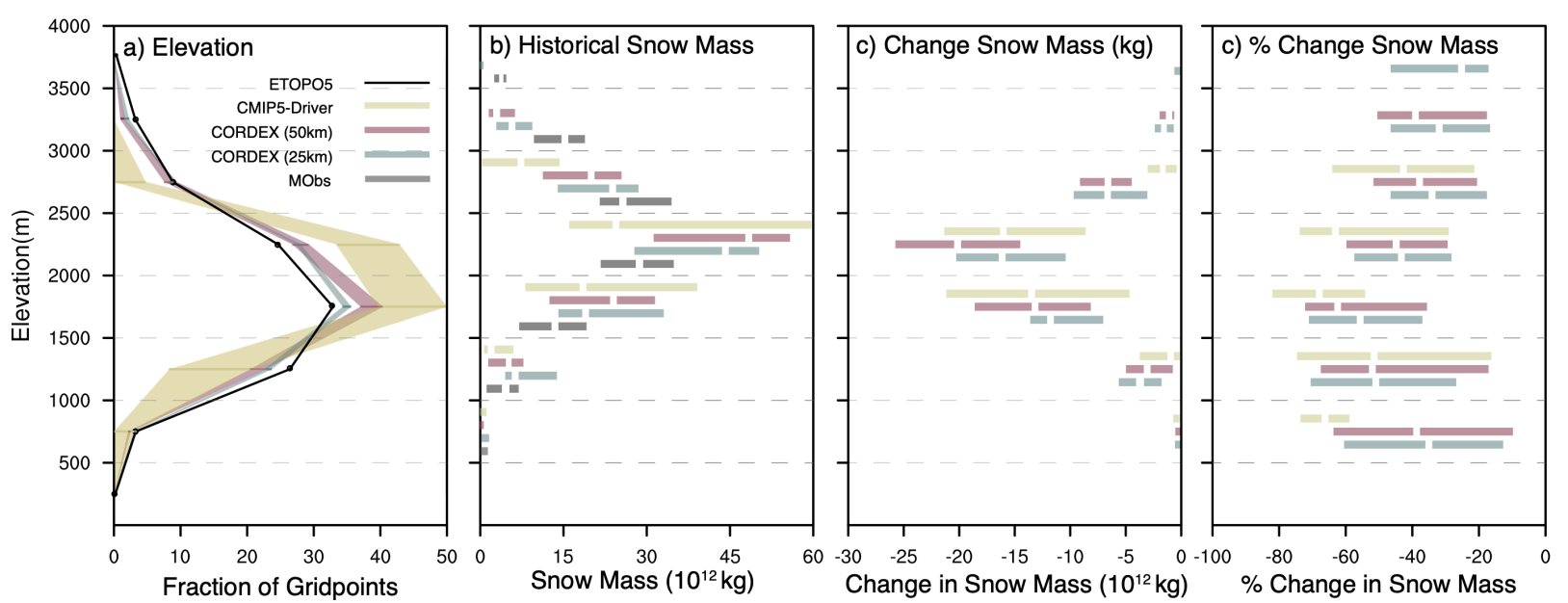

Fig. 8 The distribution of elevation for the IMW region from ETOPO5, and the three different model ensembles (a). The elevational distribution of historical AM-SM from the four MObs with the highest peak SM and the three model ensembles (b), the magnitude in future change in AM-SM (c), and the percent change in AM-SM (c). Elevation bins range from 0-4000m, incremented by $500 \mathrm{~m}$. Values are plotted between the elevation bins identified by the dashed lines. In (a) elevation is binned independently for each model using its native grid topography. The spread for each ensemble shows the minimum and maximum values calculated for each bin. In b-d the spread of each ensemble is shown, and the white space between the bars represents the ensemble mean change. 

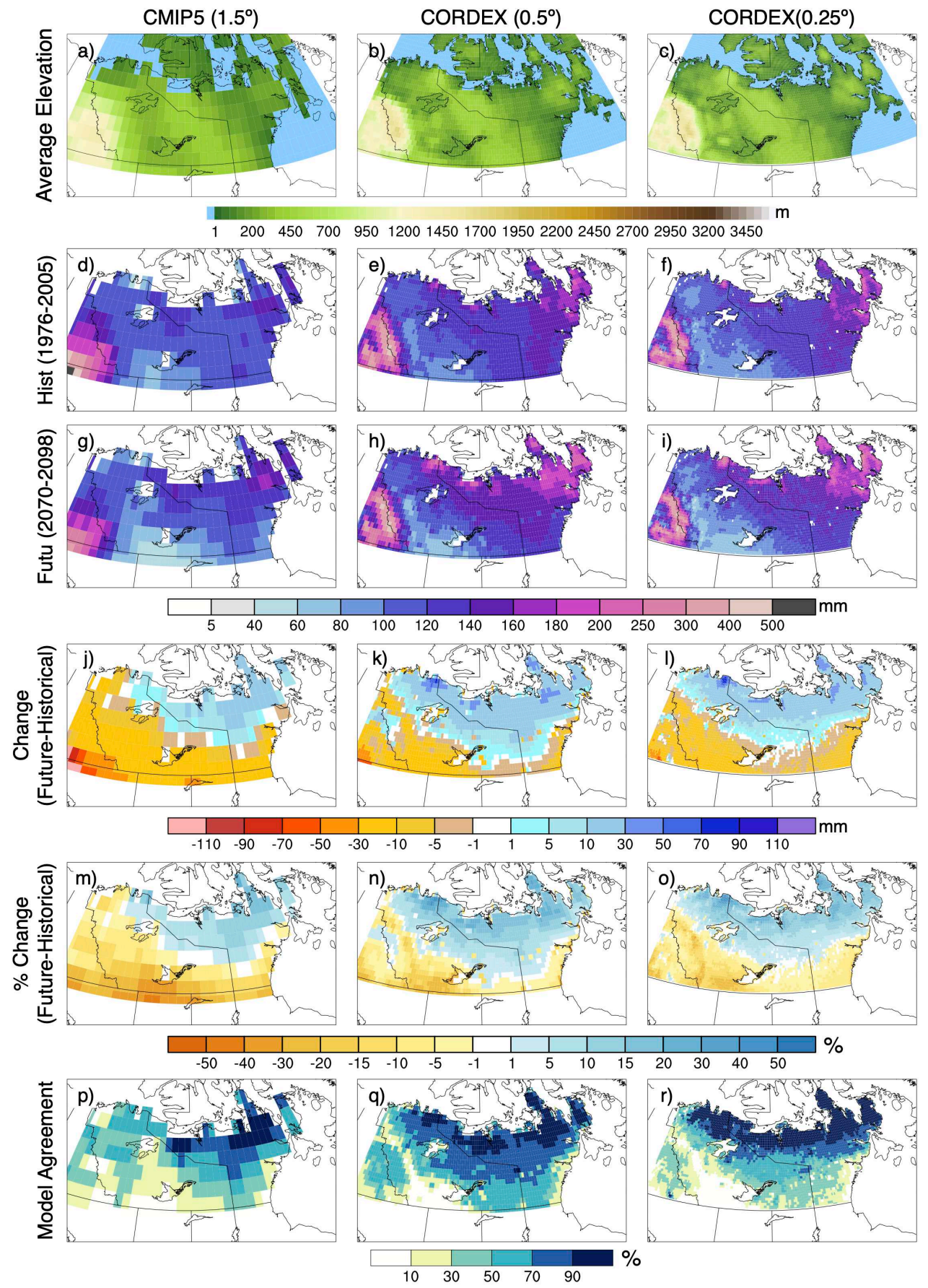

Fig. 9 Maps over the NC-Canada region of the ensemble mean topography (a-c), ensemble mean historic AM-SWE (d-f), ensemble mean future AM-SWE (g-i), the magnitude (j-1) and percent ( $\mathrm{m}-\mathrm{o}$ ) change (Future-Historic) in AM-SWE, and the percent of models in each ensemble that agree AM-SWE will increase in the future (p-r). 

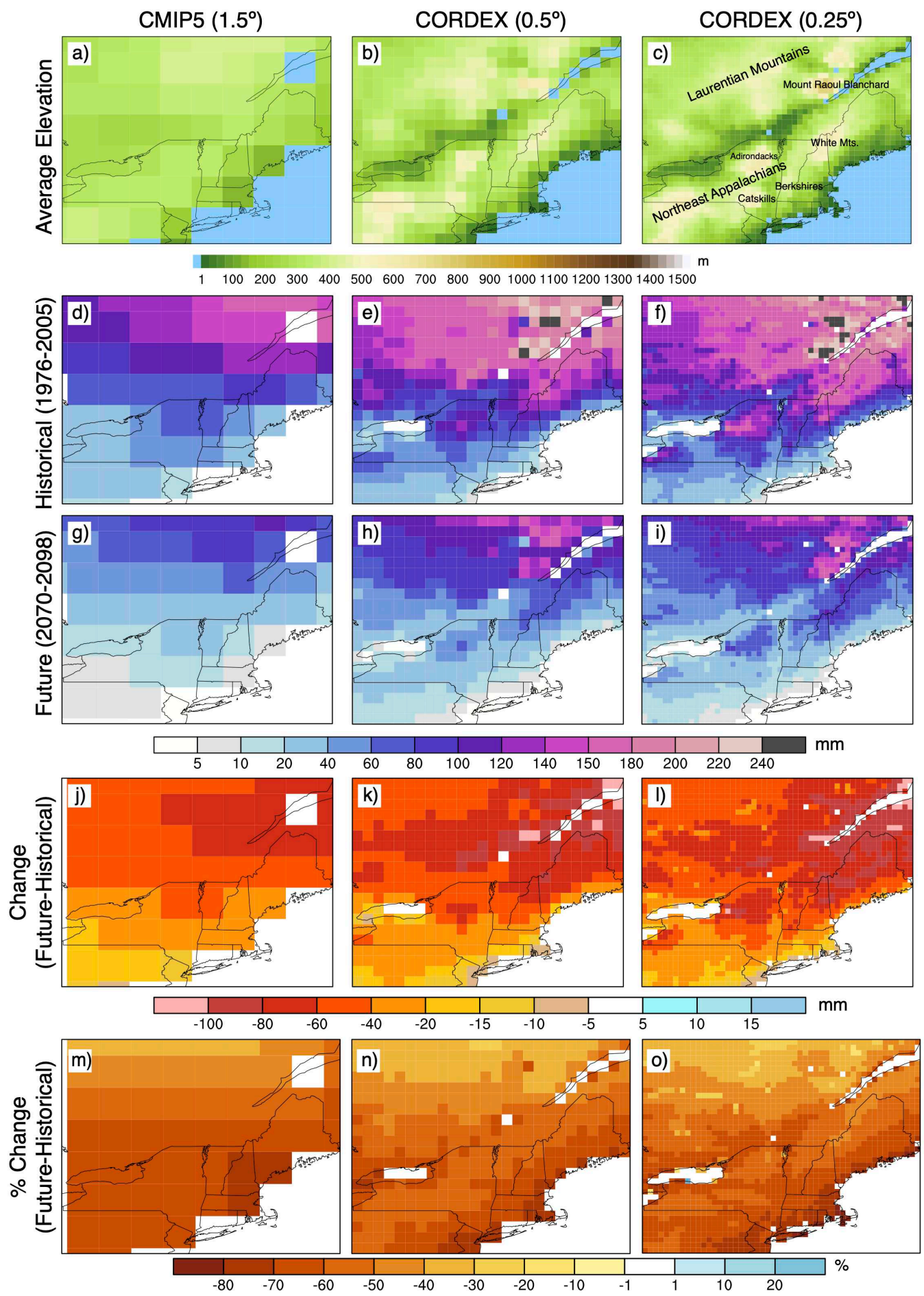

899 Fig. 10 Maps over the Northeast region of ensemble mean topography (a-c), ensemble mean

900 historic AM-SWE (d-f), ensemble mean future AM-SWE (g-i), the magnitude (j-1) and percent 901 (m-o) change (Future-Historic) in AM-SWE from the three model ensembles. 
905

906

907 


\section{Supplementary Files}

This is a list of supplementary files associated with this preprint. Click to download.

- Supplementallnformation.docx 